\title{
Estudo petrográfico e geoquímico dos ironstones da base da Formação Pimenteiras, Borda Oeste da Bacia do Parnaíba, Tocantins
}

\author{
Gabriel de Jesus Lavareda Amaro ${ }^{1 *}$, Raimundo Netuno Villas ${ }^{2}$, Basile Kotschoubey ${ }^{2}$
}

\begin{abstract}
Resumo Ironstones, que ocorrem na base da Formação Pimenteiras (Devoniano), na borda noroeste da Bacia do Parnaíba, foram investigados ao longo dos perfis Xambioá-Vanderlândia e Colinas do Tocantins-Couto Magalhães. Esses ironstones formam camadas de espessura decimétrica, descontínuas e intercaladas em arenitos e siltitos, que jazem sobre rochas do cinturão Araguaia. Além da textura oolítica, os ironstones de Xambioá-Vanderlândia diferem dos de Colinas do Tocantins-Couto Magalhães por conterem menores quantidades de material terrígeno, notadamente quartzo, e maiores proporções de oxi-hidróxidos de Fe. São ainda mais enriquecidos em V, Sr, Zr e $\Sigma_{\text {ETR }}$ e mais empobrecidos em $\mathrm{Al}_{2} \mathrm{O}_{3}$ e Rb. Diferem também no padrão de distribuição dos ETR normalizados ao North American Shale Composite (NASC), especialmente com relação aos valores de $(\mathrm{ETRI})_{\mathrm{N}}$, os quais, mais altos nos ironstones oolíticos e mais baixos nos não oolíticos, geram curvas convexas e côncavas, respectivamente. No campo, não foram estabelecidas as relações espaciais entre as duas variedades de ironstones, porém sugere-se que elas representem diferentes fácies da mesma formação ferrífera. Possivelmente, a deposição da fácies não oolítica ocorreu mais afastadamente da borda continental, em ambiente de águas mais profundas e calmas, onde foram descarregadas maiores quantidades de sedimentos detríticos; a deposição da fácies oolítica transcorreu em águas mais rasas e agitadas, com menor suprimento de material terrígeno. O transporte do Fe poderia ter resultado, em grande parte, da erosão fluvial de áreas continentais marcadas por ambientes redutores, o que teria favorecido a solubilidade daquele metal na forma de complexos orgânicos.
\end{abstract}

Palavras-chave: ironstones; Formação Pimenteiras; Bacia do Parnaíba; oólitos.

Abstract Petrographic and geochemical study of the ironstones from the base of the Pimenteiras Formation, Western border of the Paraiba Basin, Tocantins. Ironstones that occur at the base of the Devonian Pimenteiras Formation (northwestern border of the Parnaíba basin) were investigated along the Xambioá-Vanderlândia and Colinas do TocantinsCouto Magalhães sections. The ironstones consist of discontinuous decimeter-thick layers intercalated in sandstones and shales that underlie rocks of the Neoproterozoic Araguaia belt. The Xambioá-Vanderlândia ironstones are texturally and chemically quite distinct from those of the Colinas do Tocantins-Couto Magalhães area. Besides the presence of oolites, the former shows smaller amounts of terrigenous material (especially quartz) and higher iron oxide-hydroxides proportions. They also are more enriched in $\mathrm{V}, \mathrm{Sr}, \mathrm{Zr}$ and $\Sigma_{\mathrm{REE}}$, and poorer in $\mathrm{Al}_{2} \mathrm{O}_{3}$ and $\mathrm{Rb}$. The North American Shale Composite (NASC) normalized REE distribution pattern is also different, especially concerning the IREE $\mathrm{N}_{\mathrm{N}}$ values, which, being higher in the oolithic ironstones, display convex curves and, being lower in the non-oolithic ironstones, display concave ones. In the field, spatial relationships could not be defined between both ironstone types. It is then suggested that they represent different lithological facies of the same iron formation. Probably, the deposition of the non-oolithic facies occurred in deeper and quieter waters away from the continental border, where larger amounts of detrital sediments were discharged, whereas the deposition of the oolithic facies took place in shallower and more agitated waters, with less supply of terrigenous material. Iron was largely derived from the erosion of continental areas where reduced environments favored its mobilization and transport by rivers as suspended particles, colloids, and organic complexes.

Keywords: ironstones; Pimenteiras Formation; Parnaíba Basin; oolites.

\section{INTRODUÇÃOO Os depósitos de ferro de ori- gem sedimentar têm ampla distribuição geográfica e temporal, tendo sido gerados em todas as épocas geo- lógicas. São vários os tipos desses depósitos, porém as formações ferríferas bandadas e os ironstones são, eco- nomicamente, os mais importantes (Stanton 1972). As primeiras formações restringem-se ao Pré-cambriano e constituem as maiores reservas de ferro do globo}

terrestre. Os ironstones, por sua vez, desenvolveramse durante o Fanerozoico e foram expressivas fontes de ferro, particularmente no leste dos Estados Unidos e na Europa Ocidental, durante as primeiras décadas do século 20. Atualmente, voltaram a ter destaque em programas de exploração mineral, haja vista a expansão industrial chinesa que, ávida por ferro, tem também recorrido a minério de mais baixo teor.

\footnotetext{
${ }^{1}$ Curso de Pós-graduação em Geologia e Geoquímica da Universidade Federal do Pará - UFPA; Instituto Federal de Educação, Ciência e Tecnologia do Pará - IFPA, Belém (PA), Brasil. E-mail: gjla@uol.com.br

${ }^{2}$ Faculdade de Geologia do Instituto de Geociências da Universidade Federal do Pará - UFPA, Belém (PA), Brasil. E-mail: netuno@ ufpa.br, basile@ufpa.br

*Autor correspondente
} 
Dentre os ironstones, que revelam comumente textura oolítica, são clássicos os depósitos ordovicianos a devonianos da América do Norte - conhecidos como tipo Clinton -, os quais ocorrem interacamados com calcários e rochas terrígenas, e aqueles das bacias europeias de Alsace e Lorraine, do Jurássico Médio, conhecidos como tipo minette e constituídos de leitos ferruginosos intercalados em folhelhos, arenitos e margas (Stanton 1972, Guilbert \& Park Jr. 1986, Robb 2005, Bekker et al. 2010).

As teorias sobre a origem dos ironstones oolíticos não são consensuais. Os pontos de maior controvérsia envolvem a formação autóctone ou alóctone dos oólitos de oxi-hidróxidos de ferro. Para os defensores do modelo in situ, os oólitos requereriam, além da solubilização do Fe em condições oxidantes, águas rasas relativamente agitadas, possibilitando o desenvolvimento da textura concêntrica em torno de um núcleo, não raro, detrítico (Young 1989, Kimberley 1994, Sturesson et al. 2000). Outros estudiosos defendem a formação dos oólitos inicialmente em solos lateritizados e seu posterior transporte para a bacia, em geral, por via fluvial (Ambrosi \& Nahon 1986, Nahon et al. 1980, Siehl \& Thein 1989). Exemplos modernos de depósitos oolíticos de ferro são raros, mas têm sido registrados na Venezuela (Mala Pascua e El Fraile) e na Indonésia (Mahengetang), e têm permitido melhor entendimento dos processos sedimentares responsáveis pela formação dos ironstones (Kimberley 1994, Heikoop et al. 1996).

No Brasil, as ocorrências de ferro oolítico parecem restritas ao Devoniano Médio das bacias do Parnaíba (Formação Pimenteiras, Tocantins), Amazonas (rio Jatapu, Amazonas) e Paraná (Serra do Roncador, Mato Grosso) (Hennies 1969; Dardenne \& Schobbenhaus 2001). Na Bacia do Parnaíba, em particular, ironstones com textura maciça à pisolítica já foram descritos na porção basal daquela formação, entre as cidades de Paraíso do Norte e Guaraí (Ribeiro \& Dardenne 1978, Sá 1981, Ribeiro 1984).

Observações recentes permitiram constatar que alguns depósitos ferríferos estendem-se ao norte do Tocantins, marcando não somente a borda ocidental da Bacia do Parnaíba como também a base do espesso pacote das rochas sedimentares paleozoicas, que repousa sobre unidades pré-cambrianas do Cinturão Araguaia. Bons afloramentos ocorrem entre Xambioá e Vanderlândia e entre Colinas do Tocantins e Couto Magalhães (Fig. 1), os quais motivaram a realização do presente trabalho com vista a contribuir com novos dados e informações geológicas para o conhecimento dos ironstones que ocorrem na Formação Pimenteiras.

CONTEXTO GEOLÓGICO Da evolução que se estende do Siluriano ao Cretáceo, a Bacia do Parnaíba registra, além de sequências sedimentares, dois importantes pulsos magmáticos máficos mesozoicos (Milani \& Zalán 1999) e foi desenvolvida sobre terrenos pré-cambrianos dos crátons São Francisco e Amazônico, da província Borborema e do cinturão Araguaia.

O Grupo Canindé, balizado estratigraficamente pelos grupos Serra Grande (Siluriano) e Balsas (Carbonífero-Triássico), corresponde à supersequência devoniana dessa bacia e é constituído, da base ao topo, pelas formações Itaim, Pimenteiras, Cabeças, Longá e Poti, as quais revelam rochas derivadas de sedimentos depositados em ambientes de maré, marinhos rasos e fluviais (Góes \& Feijó 1994). Espessas camadas de folhelhos cinza escuros a esverdeados, contendo intercalações de arenitos finos e siltitos argilosos, além de camadas de oólitos piritosos locais, compõem a Formação Pimenteiras (Aguiar 1971). Nela também estão incluídos diamictitos, que foram interpretados como tilitos por Kegel (1953).

Na borda ocidental da Bacia do Parnaíba, os sedimentos que deram origem às rochas da Formação Pimenteiras são considerados como litorâneos a sublitorâneos (Ribeiro \& Dardenne 1978). Os sedimentos litorâneos são, atualmente, representados por: siltitos esverdeados e bioturbados, que apresentam marcas de ondas, estruturas flaser e laminação plana paralela (fácies de planície de maré) e arenitos ferruginosos oolíticos com estratificação cruzada acanalada (fácies de canal de maré), cuja porção basal inclui conglomerados, arenitos conglomeráticos, concentrações de braquiópodes e fragmentos vegetais. Os litotipos correspondentes aos sedimentos sublitorâneos são dominados por siltitos e folhelhos betuminosos com intercalações calcíferas no membro superior.

Dados sedimentológicos, fossilíferos e paleomagnéticos indicam que, entre o Devoniano e o Carbonífero Inferior, na Bacia do Parnaíba, as condições climáticas atingiram regime periglacial (Ribeiro 1984). Em mapas dos continentes, nesses períodos, aquela bacia está entre as latitudes $60^{\circ}$ e $70^{\circ} \mathrm{S}$ (Scortese et al. 1979 apud Ribeiro 1984), o que permite inferir ter sido a Formação Cabeças depositada sob condições climáticas pelo menos temperadas. 


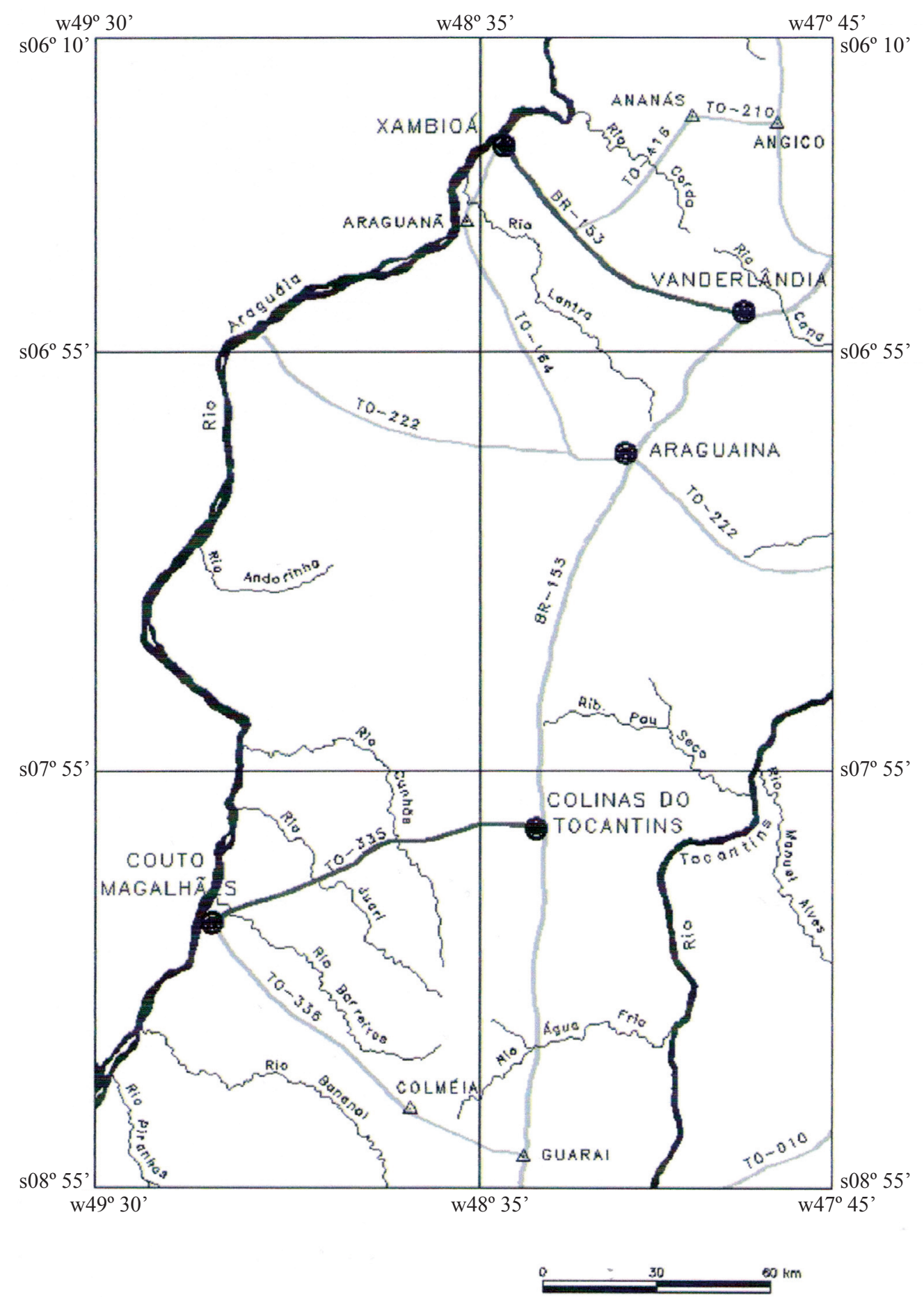

Figura 1 - Localização dos dois perfis estudados: Xambioá e Vanderlândia (rodovia BR-153) e Colinas do Tocantins-Couto Magalhães (TO-335).

Ironstones da Formação Pimenteiras $\mathrm{Na}$ região de Paraíso do Norte-Guaraí, Tocantins, foram descritos, na base da Formação Pimenteiras, leitos oolíticos ferruginosos intercalados em arenitos e siltitos (Ribeiro \& Dardenne 1978), muito semelhantes aos depósitos de tipos Minette e Clinton. Os leitos inferiores correspondem a minério de ferro cloritoso e os superiores a minério de ferro oolítico (Sá 1981).

Camadas ricas em oxi-hidróxidos de ferro e chamosita foram descritas na região entre Paraíso do Norte e Miranorte (Tocantins), cujo ferro é, em grande parte, encontrado como constituinte de oólitos 
(Ribeiro 1984). Este autor ressalta que essa fácies oolítica é difícil de ser definida, devido a variações laterais de espessura e litologia. A despeito disso, é descrito minério de ferro relacionado a várias subfácies oolíticas em que ocorrem grãos detríticos de quartzo, feldspatos, muscovita e argilominerais e minerais neoformados (limonita, clorita, calcita, além de fosfatos e sulfeto de $\mathrm{Pb}$ e $\mathrm{Zn}$ ).

Oólitos também foram registrados a oeste de Colmeia, Morro do Mato (Tocantins), em sequência sedimentar clástica paleozoica, cuja base é marcada por lentes ferro-manganesíferas que gradam lateralmente para leitos conglomeráticos (Amaro 1985).

GEOLOGIA LOCAL Nos perfis estudados (Fig. 2), ambos na borda oeste da bacia do Parnaíba, a Formação Pimenteiras repousa sobre rochas metamórficas da Formação Xambioá do Grupo Estrondo do Supergrupo Baixo Araguaia, de idade neoproterozoica (Moura \& Gaudette 1993).

Unidades litoestratigráficas basais dessa bacia distribuem-se pela região, algumas delas recobrindo o Grupo Estrondo. Constituem áreas topograficamente elevadas com característica de platôs. Em vários locais, foram formadas crostas lateríticas, as quais capeiam serras e morros, tornando os topos mais resistentes à erosão.

Região de Xambioá-Vanderlândia Boas exposições localizam-se na rodovia BR-153, no sentido de Xambioá para Vanderlândia, entre os km 29 e 31.
Nos arredores do km 31, os afloramentos da Formação Pimenteiras são compostos por camadas horizontalizadas. Em direção à cidade de Xambioá, próximo ao km 29, ocorrem rochas quartzíticas da Formação Morro do Campo (base do Grupo Estrondo), as quais se sobrepõem a micaxistos da Formação Xambioá por meio da falha de cavalgamento Andorinhas (Fig. 2A). Não há registros de rochas cambro-silurianas e tampouco da Formação Itaim na área estudada, em claro testemunho de que houve hiato estratigráfico.

A Formação Pimenteiras inicia-se com camada decimétrica de conglomerado oligomítico, que exibe seixos quartzosos de tamanhos e formas variados, envolvidos em uma matriz síltico-arenosa de coloração esbranquiçada com tons avermelhados a amarelados. Acima do conglomerado, ocorre camada argiloso-siltosa de pouco mais de $1 \mathrm{~m}$ de espessura, de cor marrom pálido, que grada, em direção à superfície, de acumulações de argilominerais misturados a oxi-hidróxidos de ferro para material siltoso, observandose, já no topo, em contato com os leitos de ironstone, grânulos e seixos esparsos angulosos, de composição ferruginosa, os quais estão envoltos por matriz arenosa composta de grãos finos de quartzo (Fig. 2A).

\section{Região de Colinas do Tocantins-Couto} Magalhães Os ironstones encontrados na rodovia TO-355 ( $\mathrm{km} 15 \mathrm{a} \mathrm{17),} \mathrm{às} \mathrm{proximidades} \mathrm{da} \mathrm{cidade}$ de Colinas do Tocantins, consistem em camadas que mergulham de 20 a $30^{\circ}$ para leste, sobrepostas por material coluvionar recente (Fig. 2B).

A
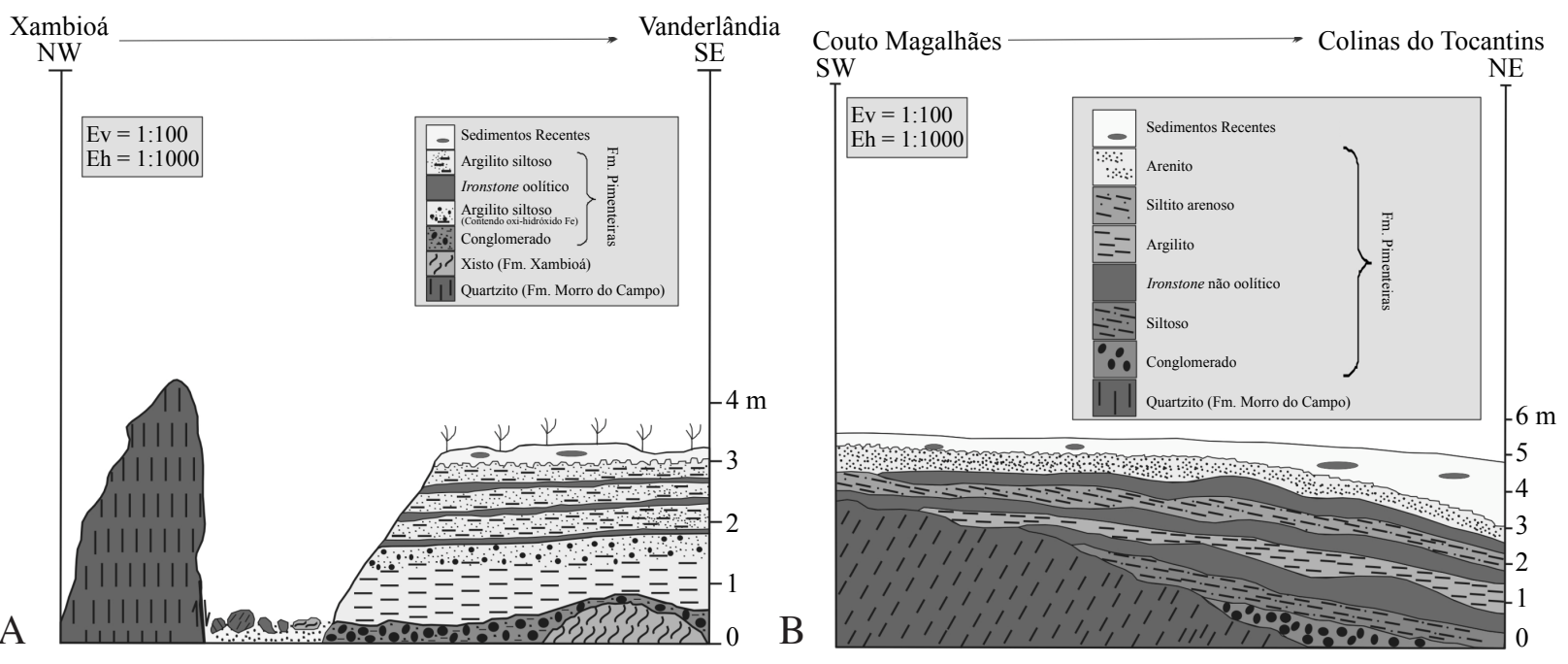

Figura 2 - Seções geológicas esquemáticas entre Xambioá e Vanderlândia (A) e entre Couto Magalhães e Colinas do Tocantins (B), mostrando os leitos de ironstones da Formação Pimenteiras, a qual está assentada discordantemente sobre as rochas do Cinturão Araguaia. 
Na porção basal, imediatamente sobre as rochas metassedimentares do Grupo Estrondo, jaz um conglomerado de matriz ferruginosa escura a marrom avermelhada, sustentando seixos silicosos arredondados a subarredondados de coloração cinza escura. Logo acima, observa-se camada homogênea de siltito com espessura de 1 a $1,5 \mathrm{~m}$ e coloração de avermelhada a arroxeada.

Os ironstones apresentam-se interestratificados com argilitos, siltitos e arenitos finos a médios. As cores mudam do vermelho forte ao amarelo intenso, denunciando a abundância de hematita e goethita, respectivamente. A camada de argilito mostra espessura de até $2 \mathrm{~m}$ e coloração esbranquiçada, que grada para siltito de tonalidade levemente lilás, com espessura máxima de $1 \mathrm{~m}$, mesclada com porções argilosas e arenosas de granulometria fina a muito fina. Em direção ao topo, encontra-se camada de arenito de coloração marrom clara a amarelada, composta por grãos de quartzo finos a médios, imersos em matriz ferruginosa.

MATERIAIS E MÉTODOS As amostras utilizadas neste estudo foram coletadas em afloramentos e submetidas a análises petrográficas e difratométricas, em laboratórios do Instituto de Geociências (IG) da Universidade Federal do Pará (UFPA), bem como analisadas quimicamente pelas técnicas de ICP-ES (Inductively Coupled Plasma Spectroscopy) e fluorescência de raios X na ACME Laboratórios Ltda. Minerais selecionados dos ironstones oolíticos foram analisados semiquantitativamente por microscopia eletrônica de varredura (MEV-EDS), no IG da UFPA.

\section{IRONSTONES OOLÍTICOS Esses ironstones} somente foram reconhecidos no perfil XambioáVanderlândia. Apresentam-se em leitos tabulares, nem sempre contínuos, com espessura de 15 a $20 \mathrm{~cm}$ e cores desde o marrom escuro ao vermelho amarronzado ou lilás. Fraturas, abertas em várias direções, são abundantes, muitas delas preenchidas por material argiloso e arenoso.

As variedades compactas são constituídas por oxi-hidróxidos de ferro com proporções subordinadas de grãos de quartzo, finos a médios e subangulares a angulares. Registram-se ondulações suaves de amplitude centimétrica, desenhadas por lâminas milimétricas de cores vermelho e amarelo. Nas porções mais friáveis dos leitos ferruginosos, observam- se estruturas convolutas, semelhantes à foliação esferoidal, que se desfazem facilmente ao leve toque do martelo.

Características dos oólitos Os oólitos quase sempre exibem estruturas concêntricas assimétricas em tons laranja forte e marrom escuro. Em menores quantidades, ocorrem oólitos sem estruturação. A abundância dos oólitos é bastante variável e o tamanho cobre a faixa de 0,2 a $0,5 \mathrm{~mm}$, alcançando excepcionalmente $1 \mathrm{~mm}$. A maioria dos oólitos está inteira, porém muitos se mostram quebrados. As formas elipsoidais são predominantes, mas as ovoides, alongadas e arredondadas são também comuns. Em algumas amostras, raros oólitos assumem forma de baguete, sem estrutura e com dimensões de até $0,5 \mathrm{~mm}$, em cujo interior estão presentes finos grãos de quartzo e palhetas de filossilicatos (Fig. 3A). Muito localmente, as dimensões alcançam $2 \mathrm{~mm}$ e caracterizam verdadeiros pisólitos, ainda que sejam sem estrutura concêntrica. Em alguns deles, observam-se tanto invaginações ocupadas por oólitos estruturados de tamanhos diversos e misturados a grãos subangulosos de quartzo, quanto oólitos de gerações anteriores (estruturados e não estruturados) em seu interior (Fig. 3C). Quando muito abundantes, os oólitos comumente se tocam e vários parecem ter sido deformados (Fig. 3B) ainda no estado plástico, sob o peso do material sobrejacente. De ocorrência local, encontram-se aglomerados de oólitos quebrados, fraturados e inteiros imersos em matriz de oxi-hidróxidos de ferro (Fig. 3D). Quando menos abundantes, os oólitos estão separados por matriz ferruginosa, de coloração escura amarronzada, que não só os envolve, como também cimenta material detrítico fino e grãos de quartzo, aleatoriamente distribuídos. Esses grãos são angulares e de bordas corroídas, e mostram-se fraturados e com extinção ondulante, alguns deles sendo maiores que os próprios oólitos. A matriz detrítica fina apresenta, além dos grãos de quartzo, placas de mineral micáceo.

É comum o núcleo dos oólitos ser ocupado por grãos detríticos, porém alguns desses grãos estão lateralmente deslocados (Fig. 3E), o que provavelmente significa que foram incorporados após o início do crescimento dessas microestruturas. Raros oólitos revelam núcleos constituídos por fragmentos de oólitos preexistentes (Fig. 3F), fragmentos esses também observados na matriz. Os grãos detríticos são dominados por quartzo (Fig. 3G), seguidos por zircão 

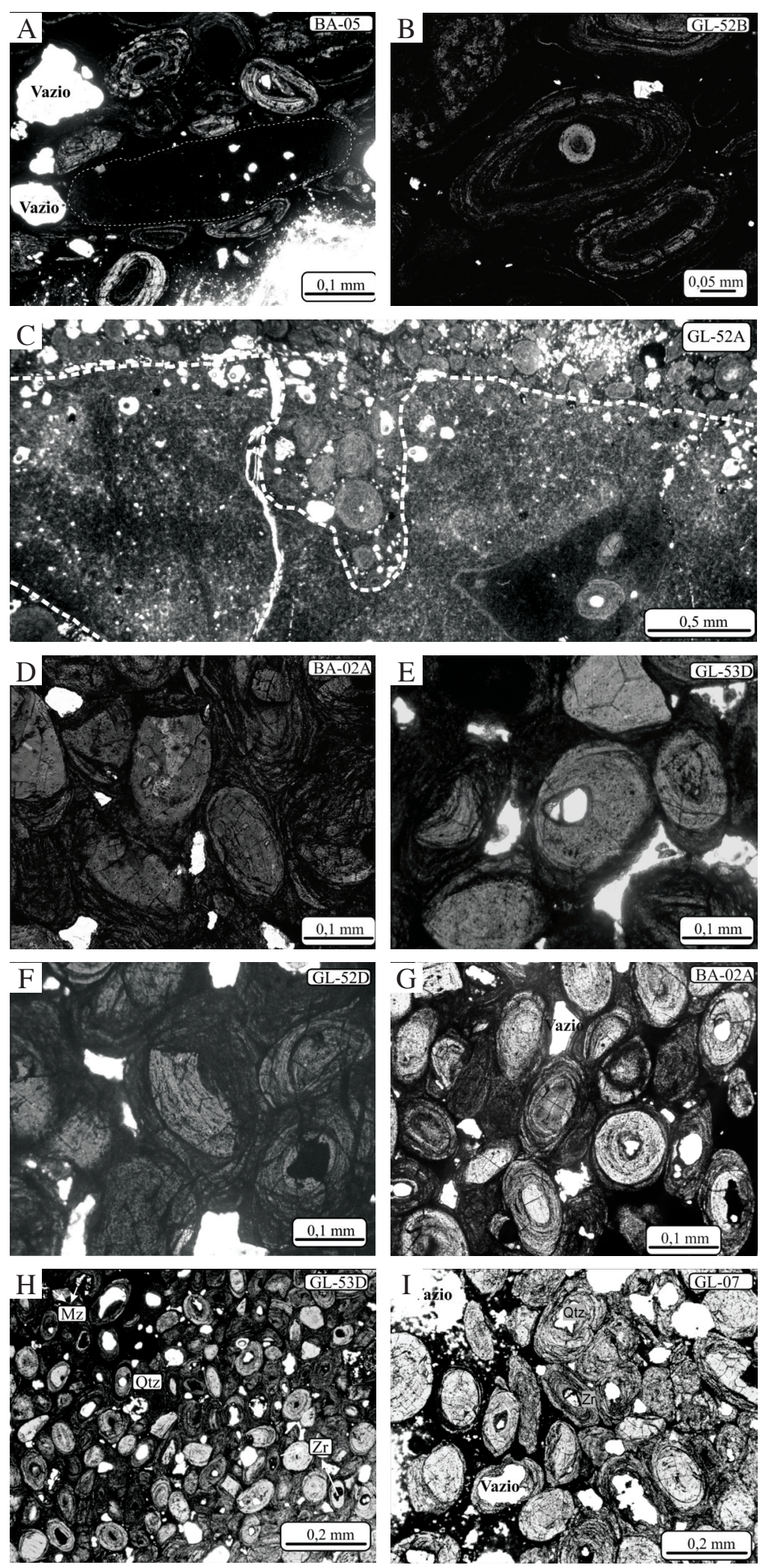

Figura 3 - Fotomicrografias de ironstones oolíticos da Formação Pimenteiras. (A) macro-oólito não estruturado de oxi-hidróxido de ferro (parte central) com forma de baguete e finos grãos de quartzo em seu interior, envoltos por oólitos menores estruturados; (B) oólitos elípticos a ovais, um dos quais apresenta núcleo esférico também de oxi-hidróxido de ferro; (C) pisólito $(\sim 9 \mathrm{~mm})$ com oólitos preexistentes inclusos, além de invaginação preenchida por oólitos esféricos e grãos de quartzo; (D) oólitos quebrados e inteiros, sem núcleos definidos, em matriz de material ferruginoso; (E) oólito com grão de quartzo deslocado do núcleo central; (F) oólito estruturado assimetricamente ao redor de fragmento de oólito preexistente também estruturado; $(G)$ agregado de oólitos de oxi-hidróxido de ferro densamente empilhados, alguns com núcleos ocupados por grãos de quartzo; (H) oólitos contendo grãos de zircão, monazita e quartzo em seus núcleos; e (I) oólitos arredondados e alongados, alguns com zircão (Zr) e quartzo (Qtz) no núcleo central. Luz transmitida. Nicois //. 
e, raramente, por monazita (Fig. 3H). Os grãos de quartzo apresentam formas variadas, desde angulosas (maioria) até arredondadas (menos comuns) e, via de regra, mostram franjas ou bordas corroídas. Poucos grãos de zircão preservam as linhas de zoneamento ou as características de terminações piramidais. Raros são aqueles encontrados inteiros (Fig. 3I).

\section{Composição mineralógica Os ironstones oo-} líticos são dominados por hematita e goethita, mas também ocorrem, subordinadamente, quartzo, zircão, argilominerais, monazita, ilmenita, magnetita e goiazita.

Hematita e goethita são os principais constituintes tanto dos oólitos quanto da matriz. Análises semiquantitativas do material ferruginoso dos oólitos
(Anexo) revelam teores de $\mathrm{Al}(1,4 \mathrm{a} 4,3 \%)$ bem maiores do que os de $\mathrm{Si}(0,2$ a $1,8 \%)$. É possível que se trate de mistura de cristais muito finos de diversos minerais (oxi-hidróxidos de ferro, titânio ou manganês e filossilicatos degradados) ou de compostos complexos e cátions adsorvidos. Outra possibilidade é ser a goethita rica em Al (Mendelovici et al. 1979). A propósito, trabalhos recentes comprovam a substituição de $\mathrm{Fe}^{+3}$ por $\mathrm{Al}^{+3}$ no sítio tetraédrico das estruturas de óxidos e de hidróxidos de Fe (Ohkawa et al. 2007; Blanch et al. 2008).

No presente estudo, picos da goethita registrados nos difratogramas (4,17 a 4,16 e 2,44 a 2,43) estão deslocados em relação aos principais (4,18 e 2,45), dando consistência à hipótese da presença de Al-goethita (Solymar 1969). Os teores de V,
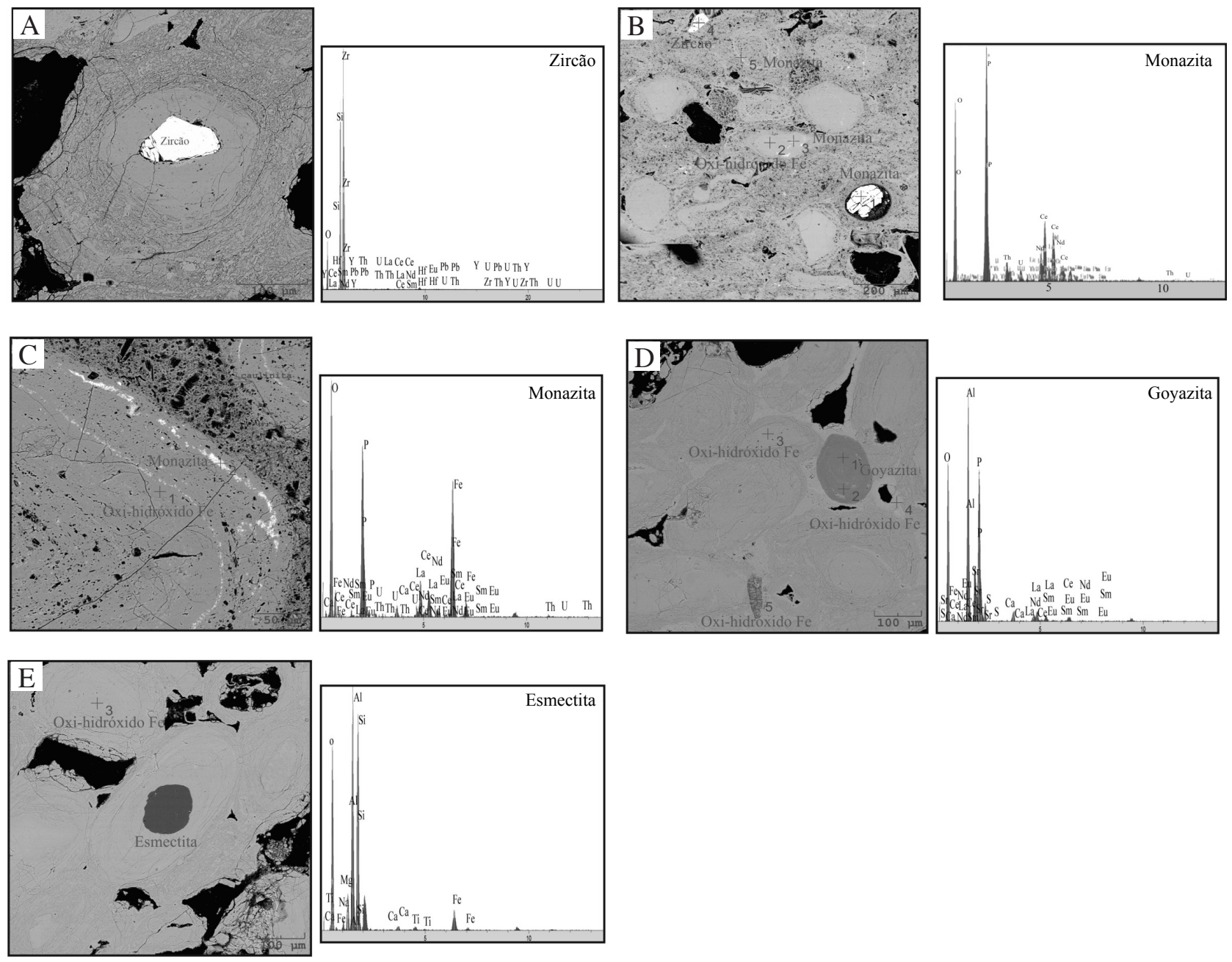

Figura 4 - Imagens de elétrons retroespalhados (MEV-EDS). (A) grão subarredondado de zircão em núcleo de oólito hematítico-goethítico, com respectivo espectro EDS; (B) grão detrítico de monazita imerso na matriz e seu respectivo espectro EDS; (C) agregado de finos cristais de monazita acompanhando a estruturação concêntrica dos oólitos; no canto superior direito, cristais de caulinita na forma de booklets dentro de matriz ferruginosa; ao lado, o espectro EDS da monazita com possivel interferência de outros elementos; (D) raro cristal de goiasita envolto por oxi-hidróxidos de ferro com respectivo espectro EDS; e (E) núcleo de argilomineral (esmectita?) com respectivo espectro EDS. 
que alcançam $0,5 \%$, podem resultar da adsorção de $\mathrm{V}$ em goethita, o que tem sido demonstrado experimentalmente em soluções aquosas de muito ácidas $(\mathrm{pH}=1,5)$ a muito básicas $(\mathrm{pH}=12)$, sob condições atmosféricas (Peacock \& Sherman 2004). Com relação ao $\mathrm{P}$, sua distribuição é errática, tanto que, em algumas análises, não foi detectado, enquanto que, em outras, suas concentrações cobrem a faixa de 0,2 a $3,6 \%$. Muito provavelmente, o $\mathrm{P}$ também se encontra adsorvido nos oxi-hidróxidos de Fe (Lijklema 1980, Byrne \& Kim 1990).

Quartzo, sempre de origem detrítica, é o mineral mais abundante depois da goethita e da hematita. $\mathrm{Na}$ matriz, seus grãos alcançam dimensões entre 160 e $200 \mu \mathrm{m}$, enquanto que, nos núcleos dos oólitos, são inferiores a $100 \mu \mathrm{m}$.

Grãos incolores de zircão, arredondados a subarredondados, com tamanhos entre 5 e $100 \mu \mathrm{m}$, ocorrem tanto no núcleo de oólitos (em geral $>30 \mu \mathrm{m}$; Fig. 4A) como na matriz (entre 5 e $30 \mu \mathrm{m}$ ). Hf ocorre em concentração significativa (1,1 a 2,3\%), em consonância com sua tão bem conhecida afinidade geoquímica com o Zr. Os teores de Th e U, juntos, não somam $0,5 \%$, com o $\mathrm{U}$, em geral, em quantidades bem maiores. Por sua vez, o Pb revela teores que variam entre 1,0 e $1,8 \%$ e certamente provém da desintegração radioativa do $\mathrm{U}$ e Th. A concentração total dos ETR varia de 4,0 a 5,9\% e, dentre eles, Dy e Eu apresentam os mais elevados teores com médias de 0,76 e $0,53 \%$, respectivamente (Anexo). Ademais, os ETRI ( $\mathrm{Sm}$ a Ho) registram teores médios de 2,42\%, o dobro dos ETRP (Er a Lu), contrariando o fato de o zircão ser, normalmente, mais enriquecido em ETRP do que em ETRI (Henderson 1984).

A ilmenita forma grãos subarredondados a subangulares, com dimensões entre 10 e $200 \mu \mathrm{m}$. As análises semiquantitativas detectaram $\mathrm{V}(0,5-0,7 \%)$ e Mn $(0,2-0,7 \%)$ e, localmente, também $\mathrm{Al}(5 \%)$ e Si $(0,8 \%)$.

A magnetita mostra formas irregulares, comumente pontiagudas, bem como tamanho pouco superior a $200 \mu \mathrm{m}$. O espectro Energy Dispersive Spectroscopy (EDS) apresenta picos elevados de Ti, alguns correspondendo a teores entre 3,5 e 8,3\% (Timagnetita?). Os teores de $\mathrm{V}$ e Mn não ultrapassam, em geral, $0,5 \%$.

Dentre os fosfatos, destacam-se a monazita e a goiazita. A monazita ocorre em grãos isolados e em finos agregados. Os grãos isolados são arredondados a subangulosos e mostram tamanhos de 100 a $220 \mu \mathrm{m}$
(Fig. 4B). São enriquecidos em ETRL ( $\mathrm{Ce}=26,8 \%$; $\mathrm{La}=9,96 \% ; \mathrm{Nd}=9,1 \%)$ e em $\mathrm{Th}(5,4 \%)$. As somas dos ETRP e ETRI fornecem 3,82 e 1,54\%, respectivamente, com destaque para os teores de $\mathrm{Lu}(1,77 \%)$, $\operatorname{Tm}(0,97 \%)$ e $\mathrm{Gd}(0,85 \%)$. Os agregados tendem a acompanhar as estruturas concêntricas dos oólitos (Fig. 4C) de modo mais e menos contínuo, indicando que este fosfato não é detrítico, mas coprecipitado com o material ferruginoso das camadas mais externas dos oólitos. Os altos teores de Fe, obtidos na maioria das análises semiquantitativas desses agregados (Anexo), são indicativos de que o feixe dos raios $\mathrm{X}$ deve ter ultrapassado os limites dos cristais deste fosfato, sendo os resultados, nestes casos, de pouco valor.

A goiazita $\left[\mathrm{SrAl}_{3}\left(\mathrm{PO}_{4}\right)_{2}(\mathrm{OH})_{5} \cdot \mathrm{H}_{2} \mathrm{O}\right]$ é mais rara e ocorre em grãos arredondados com tamanho acima de $150 \mu \mathrm{m}$, sem que ocupem o núcleo de oólitos (Fig. 4D). Esse fosfato foi assim identificado, no espectro EDS, pelos picos marcantes de $\mathrm{Sr}, \mathrm{Al}$ e $\mathrm{P}$, juntos, dos quais também sobressaem os de La e Ce. Análises semiquantitativas registram teores médios de 7,7\% (Sr), 3,5\% (La) e 5,8\% (Ce). Chamam atenção, em particular, as concentrações de $\mathrm{S}(0,5$ $1,7 \%)$ e de $\mathrm{Fe}(1,6-8,8 \%)$, as quais que podem sugerir tendência de solução sólida com a alunita-jarosita $\left[\mathrm{K}\left(\mathrm{Al}, \mathrm{Fe}^{3+}\right)_{3}\left(\mathrm{SO}_{4}\right)_{2}(\mathrm{OH})_{6}\right]$.

Os argilominerais ocorrem na matriz que sustenta os oólitos, porém em quantidades bem subordinadas em relação às dos oxi-hidróxidos de ferro. Mostram formas e tamanhos variados: tubulares $(30-40 \mu \mathrm{m})$, retangulares a quadradas $(10-15 \mu \mathrm{m}) \mathrm{e}$ irregulares $(>10 \mu \mathrm{m})$, sendo as últimas as mais abundantes. Observam-se, também, intercrescimentos de minúsculos cristais que se organizam em folhas paralelas (booklets), típicos do mineral caulinita.

Em apenas uma amostra (GL-53d), foi observado argilomineral como núcleo central de um único oólito, com tamanho de pouco mais de $100 \mu \mathrm{m}$ e forma arredondada (Fig. 4E). A presença de picos referentes ao $\mathrm{Ca}, \mathrm{Mg}, \mathrm{Na}$ e $\mathrm{K}$ no espectro EDS permite supor tratar-se de variedade do grupo da esmectita.

Composição química Foram analisadas 13 amostras de ironstones oolíticos, oriundas da região de Xambioá-Vanderlândia (Tab. 1). Os principais componentes desses ironstones são $\mathrm{SiO}_{2} \mathrm{e} \mathrm{Fe}_{2} \mathrm{O}_{3}$ (todo $\mathrm{Fe}$ como $\mathrm{Fe}^{+3}$ ), os quais somam mais de $75 \%$, com $\mathrm{Fe}_{2} \mathrm{O}_{3}$ variando de 62,5 a $79 \%$ e $\mathrm{SiO}_{2} 3$ a $15,3 \%$. À parte a perda ao fogo $(9,4$ a $13,5 \%)$, outro componente 
Tabela 1 - Composição química de amostras de ironstone oolítico da Formação Pimenteiras (região de Xambioá). Elementos maiores em \% (peso); elementos terras raras e traços em ppm, exceto Au em ppb

\begin{tabular}{|c|c|c|c|c|c|c|c|c|c|c|c|c|c|}
\hline & GL01 & GL02 & GL07 & BA-02A & BA-03 & BA-04 & BA-05 & GL-52A & GL-52B & GL-53A & GL-53B & GL-53C & GL-53D \\
\hline $\mathrm{SiO}_{2}$ & 12,60 & 13,07 & 14,38 & 3,02 & 15,2 & 15,28 & 2,85 & 6,14 & 12,16 & 7,11 & 11,1 & 13,06 & 3,36 \\
\hline $\mathrm{TiO}_{2}$ & 0,49 & 0,44 & 0,62 & 0,23 & 0,7 & 0,61 & 0,25 & 0,16 & 0,19 & 0,32 & 0,75 & 0,83 & 0,51 \\
\hline $\mathrm{Al}_{2} \mathrm{O}_{3}$ & 6,26 & 6,45 & 6,59 & 4,39 & 9,24 & 6,32 & 4,66 & 6,18 & 6,48 & 6,24 & 7,67 & 7,74 & 4,36 \\
\hline $\mathrm{Fe}_{2} \mathrm{O}_{3}$ & 64,89 & 64,50 & 67,20 & 78,97 & 64,54 & 64,4 & 78 & 71,23 & 66,09 & 71,3 & 65,48 & 62,55 & 76,36 \\
\hline $\mathrm{MgO}$ & 0,01 & 0,01 & 0,01 & 0,06 & 0,01 & 0,02 & 0,06 & 0,01 & 0,03 & 0,04 & 0,01 & 0,01 & 0,05 \\
\hline $\mathrm{CaO}$ & 0,14 & 0,12 & 0,05 & 0,02 & 0,01 & 0,05 & 0,03 & 0,03 & 0,01 & 0,01 & 0,01 & 0,02 & 0,02 \\
\hline $\mathrm{Na}_{2} \mathrm{O}$ & 0,01 & 0,01 & 0,01 & 0,02 & 0,01 & 0,01 & 0,01 & 0,01 & 0,02 & 0,02 & 0,01 & 0,01 & 0,02 \\
\hline $\mathrm{K}_{2} \mathrm{O}$ & 0,13 & 0,10 & 0,06 & 0,04 & 0,1 & 0,05 & 0,04 & 0,08 & 0,06 & 0,06 & 0,05 & 0,04 & 0,01 \\
\hline $\mathrm{MnO}$ & 0,04 & 0,04 & 0,05 & 0,05 & 0,46 & 0,04 & 0,06 & 0,06 & 0,06 & 0,13 & 0,06 & 0,07 & 0,08 \\
\hline $\mathrm{P}_{2} \mathrm{O}_{5}$ & 3,25 & 3,07 & 0,87 & 0,85 & 0,46 & 1,73 & 1,28 & 2,23 & 1,81 & 1,03 & 1,48 & 2,43 & 1,72 \\
\hline $\mathrm{Cr}_{2} \mathrm{O}_{3}$ & 0,03 & 0,03 & 0,05 & 0,16 & 0,045 & 0,04 & 0,016 & 0,032 & 0,04 & 0,039 & 0,075 & 0,078 & 0,049 \\
\hline $\mathrm{PF}$ & 11,60 & 11,70 & 9,50 & 12,5 & 9,4 & 11,3 & 12,7 & 13,5 & 12,6 & 13,4 & 12,8 & 12,5 & 13,1 \\
\hline Total & 99,45 & 99,54 & 99,39 & 100,31 & 100,18 & 99,85 & 99,96 & 99,66 & 99,55 & 99,70 & 99,50 & 99,34 & 99,64 \\
\hline $\mathrm{La}$ & 193,00 & 210,20 & 91,20 & 90,7 & 117,9 & 223,7 & 102,4 & 91 & 140,1 & 16,5 & 123,2 & 246 & 85,6 \\
\hline $\mathrm{Ce}$ & 548,20 & 554,30 & 201,80 & 187,5 & 217,1 & 655,6 & 260 & 294,1 & 433,6 & 59,1 & 284 & 741,7 & 163,1 \\
\hline $\mathrm{Pr}$ & 69,63 & 66,50 & 20,96 & 19,61 & 18,22 & 76,94 & 26,91 & 32,2 & 45,89 & 4,8 & 32,12 & 85,58 & 16,06 \\
\hline $\mathrm{Nd}$ & 314,70 & 280,70 & 84,10 & 70,8 & 54,7 & 291 & 99,2 & 131,9 & 192,1 & 21,3 & 121,5 & 366,9 & 55,7 \\
\hline $\mathrm{Sm}$ & 72,24 & 60,22 & 18,12 & 15,53 & 9,9 & 52,7 & 19,2 & 27,25 & 34,9 & 5,48 & 22,3 & 66,9 & 10,47 \\
\hline $\mathrm{Eu}$ & 16,58 & 13,98 & 4,56 & 3,32 & 1,98 & 11,79 & 4,07 & 5,51 & 7,34 & 1,33 & 4,51 & 13,43 & 2,22 \\
\hline $\mathrm{Gd}$ & 77,15 & 60,79 & 18,50 & 13,73 & 8,78 & 41,19 & 16,54 & 20,33 & 26,48 & 6,75 & 16,98 & 45,23 & 9,71 \\
\hline $\mathrm{Tb}$ & 10,70 & 8,84 & 3,07 & 2,02 & 1,79 & 6,42 & 2,92 & 2,63 & 3,33 & 1,21 & 2,32 & 5,52 & 1,42 \\
\hline Dy & 52,67 & 46,70 & 17,96 & 13,27 & 11,16 & 28,91 & 14,94 & 15,07 & 18,95 & 9,69 & 14,66 & 28,37 & 9,62 \\
\hline Ho & 8,10 & 7,63 & 3,14 & 2,44 & 2,04 & 4,3 & 2,31 & 2,45 & 3,09 & 2,04 & 2,63 & 4,28 & 1,81 \\
\hline Er & 19,21 & 17,86 & 8,97 & 7,43 & 6,74 & 11,97 & 6,77 & 7,26 & 8,99 & 6,55 & 7,52 & 11,15 & 5,7 \\
\hline $\mathrm{Tm}$ & 2,37 & 2,22 & 1,28 & 1,14 & 1,11 & 1,83 & 1,05 & 1,15 & 1,45 & 1,02 & 1,2 & 1,71 & 0,88 \\
\hline $\mathrm{Yb}$ & 13,34 & 12,61 & 8,99 & 7,8 & 7,55 & 12,68 & 6,82 & 7,84 & 10,09 & 6,82 & 8,21 & 11,27 & 6,03 \\
\hline $\mathrm{Lu}$ & 1,61 & 1,50 & 1,15 & 1,1 & 1,11 & 1,81 & 1 & 1,12 & 1,4 & 1,02 & 1,16 & 1,58 & 0,85 \\
\hline$\Sigma$ ETR & $1.399,50$ & $1.344,05$ & 483,80 & 436,39 & 460,08 & $1.420,84$ & 564,13 & 639,81 & 927,71 & 143,61 & 642,31 & $1.629,62$ & 369,17 \\
\hline $\mathrm{Ba}$ & 266,00 & 248,00 & 62,00 & 70 & 131,7 & 57 & 87,8 & 86 & 25 & 29 & 39 & 55 & 53 \\
\hline $\mathrm{Sr}$ & 295,90 & 271,00 & 168,30 & 123,7 & 233,1 & 171,79 & 140,5 & 85,9 & 26,5 & 15 & 116,5 & 132,6 & 127,7 \\
\hline $\mathrm{Rb}$ & 6,10 & 5,10 & 2,20 & 0,3 & 4,2 & 2,3 & 0,5 & 11,3 & 2,2 & 2,1 & 1,5 & 1,8 & 0,3 \\
\hline $\mathrm{Zr}$ & 324,50 & 243,80 & 484,10 & 353,2 & 601 & 518,2 & 297,2 & 125 & 172,7 & 211,9 & 513,7 & 588 & 393,8 \\
\hline $\mathrm{Y}$ & 181,20 & 165,40 & 62,60 & 49 & 53,1 & 102,4 & 54,9 & 46,7 & 64,2 & 41,9 & 56,6 & 86,3 & 38,9 \\
\hline $\mathrm{Nb}$ & 12,00 & 11,80 & 16,40 & 12,7 & 19,3 & 12,9 & 10,4 & 6,5 & 13,1 & 7,2 & 17,9 & 20,4 & 13,2 \\
\hline Hf & 8,70 & 7,20 & 12,90 & 8,6 & 15,2 & 12,7 & 7,5 & 3,3 & 4 & 6 & 13,1 & 14,7 & 10 \\
\hline $\mathrm{Ga}$ & 17,30 & 19,70 & 21,00 & 14,5 & 22,5 & 19,1 & 15,5 & 11,4 & 11,3 & 12,8 & 22,2 & 22,4 & 16,9 \\
\hline Th & 23,50 & 23,10 & 39,40 & 24,5 & 45,2 & 42 & 24,2 & 19,2 & 26,4 & 23,5 & 32,6 & 38,3 & 25,7 \\
\hline $\mathrm{Ta}$ & 0,70 & 0,90 & 0,90 & 0,7 & 0,8 & 0,6 & 0,4 & 0,3 & 0,3 & 0,5 & 0,9 & 1,1 & 0,6 \\
\hline $\mathrm{Ni}$ & 20,00 & 40,00 & 50,00 & 59 & 23,3 & 40,2 & 31,3 & 69 & 49 & 63 & 225 & 59 & 42 \\
\hline $\mathrm{Cr}$ & 280 & 290 & 490 & 160 & 450 & 400 & 160 & 320 & 400 & 390 & 750 & 780 & 490 \\
\hline Cs & 0,4 & 0,3 & 0,1 & 0,1 & 0,1 & 0,2 & 0,1 & 0,2 & 0,1 & $<0,1$ & $<0,1$ & 0,1 & $<0,1$ \\
\hline $\mathrm{V}$ & 1.259 & 1.456 & 1.988 & 783 & 1.279 & 1.654 & 1.065 & 1.032 & 1.462 & 829 & 1.333 & 1.806 & 1.179 \\
\hline $\mathrm{U}$ & 7,5 & 6,5 & 6,6 & 7,3 & 9,8 & 9,5 & 9 & 7,2 & 8,6 & 11,7 & 10,7 & 9,9 & 11,3 \\
\hline Mo & 1,5 & 1,6 & 2,4 & 2,6 & 3,3 & 1,4 & 2,2 & 3,2 & 4,2 & 6,1 & 1,8 & 3,7 & 3,4 \\
\hline $\mathrm{Cu}$ & 14,1 & 11 & 10,1 & 5,7 & 23 & 6,9 & 6,5 & 18,5 & 12,0 & 16,8 & 12,6 & 13,4 & 14,1 \\
\hline $\mathrm{Pb}$ & 4,9 & 5,8 & 18,9 & 8,2 & 9 & 14,3 & 12,7 & 29,4 & 39,6 & 19,8 & 25,9 & 19,1 & 30,2 \\
\hline $\mathrm{Zn}$ & 88 & 89 & 87 & 71 & 45 & 68 & 76 & 77 & 59 & 79 & 52 & 88 & 116 \\
\hline $\mathrm{Bi}$ & 0,4 & 0,4 & 0,5 & 0,4 & 0,6 & 0,6 & 0,3 & 0,8 & 0,5 & 0,5 & 1,0 & 0,7 & 0,5 \\
\hline $\mathrm{Au}$ & 1,9 & 6,7 & 4,2 & 2,3 & 1,2 & 1,2 & 2,3 & 1,0 & $<0,5$ & 1,7 & $<0,5$ & 18,7 & $*$ \\
\hline As & 54,7 & 44,6 & 52,4 & 7,9 & 7,4 & 154,9 & 11,2 & 66,5 & 57,4 & 98,5 & 59,8 & 70,1 & 32,4 \\
\hline $\mathrm{Be}$ & 8 & 8 & 4 & 5 & 2 & 9 & 8 & 5 & 5 & 8 & 2 & 3 & 6 \\
\hline Co & 11,20 & 17,5 & 19,9 & 6,1 & 6,1 & 17,8 & 6,3 & 24,8 & 23,0 & 27,6 & 15,5 & 13,5 & 14,4 \\
\hline $\mathrm{W}$ & $<1,4$ & 14,8 & 1,9 & 12 & 3 & 10,1 & 14 & 3,2 & 10,9 & 5,8 & 4,3 & 2,6 & 6,2 \\
\hline $\mathrm{Sc}$ & 22 & 24 & 33 & 23 & 24 & 28 & 28 & 34 & 39 & 40 & 28 & 33 & 38 \\
\hline
\end{tabular}



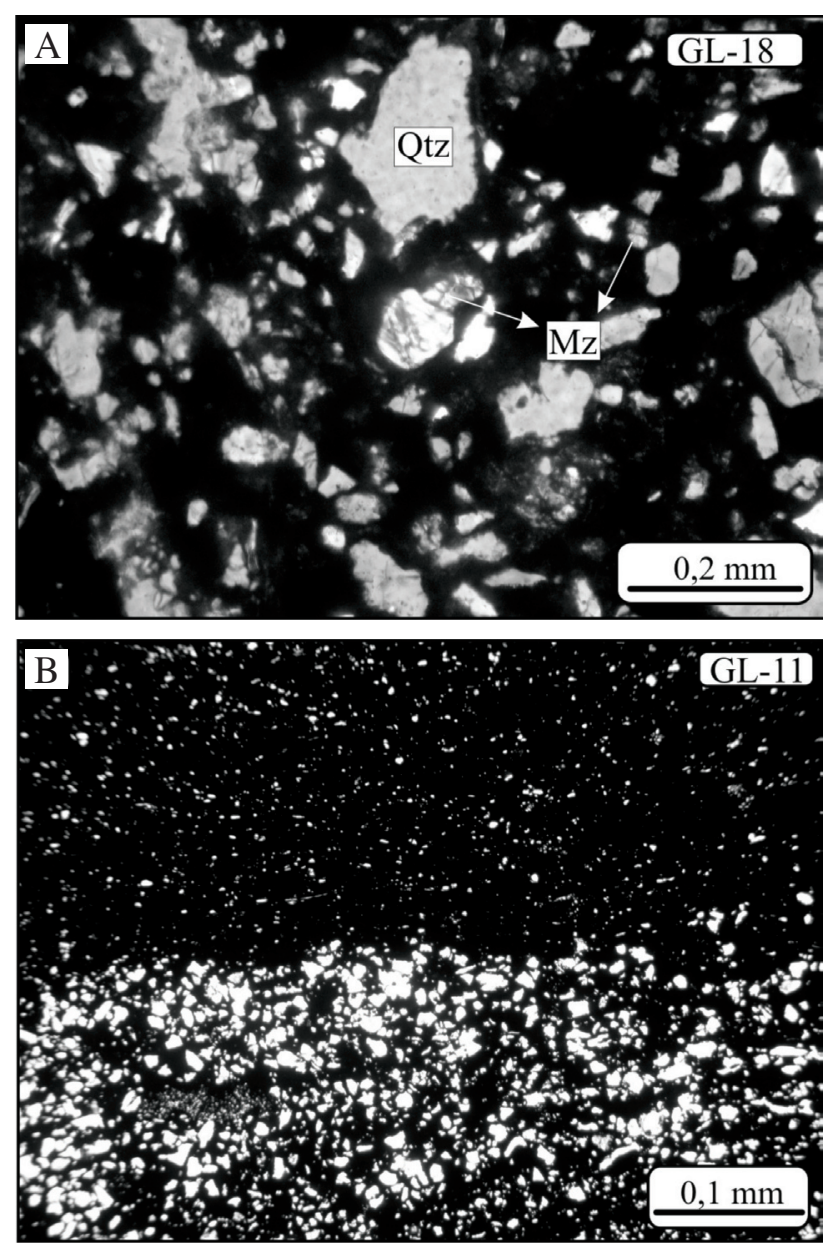

Figura 5 - Fotomicrografias de amostras de ironstone não oolítico. (A) grão de monazita (Mz) com forma de fruto de caju junto a grãos subangulosos de quartzo (Qtz); e (B) laminação plano-paralela destacada pela alternância de microleitos enriquecidos $e$ empobrecidos em grãos de quartzo e cimentados por material hematítico-goethítico. Nicois //.

de maior de expressão é o $\mathrm{Al}_{2} \mathrm{O}_{3}$, cujo teor cobre a faixa de 4,4 a $9,2 \%$. Os demais componentes registram valores inferiores a $0,1 \%$, à exceção do $\mathrm{P}_{2} \mathrm{O}_{5}$, que, em geral, está presente com concentrações pouco acima de $1 \%$, embora chegue a alcançar 3,25\%. Estas variações certamente refletem tanto os diferentes conteúdos modais dos constituintes minerais das amostras analisadas, quanto o maior ou o menor grau da adsorção de certos elementos na superfície desses minerais.

Com relação aos elementos traços, as análises revelam teores expressivos apenas para alguns deles. Considerando os teores médios, são registrados 1.353 ppm (V), 323 ppm (Zr), 147 ppm (Sr), 91 ppm (Ba), 62 ppm (Ni), 30 ppm (Th), 18 ppm (Ga) e 9 ppm (U e Hf). No caso particular dos ETR, os leves são mais abundantes, constatando-se que $\mathrm{Ce}>>\mathrm{La}$,
Tabela 2 - Composição química de amostras de ironstone não oolítico da Formação Pimenteiras (região de Colinas do Tocantins). Elementos maiores em \% (peso); elementos terras raras e traços em ppm, exceto Au em ppb

\begin{tabular}{|c|c|c|c|c|c|}
\hline & GL11 & GL12 & GL13 & GL17 & GL18 \\
\hline $\mathrm{SiO}_{2}$ & 38,9 & 15,9 & 39,1 & 35,9 & 25,8 \\
\hline $\mathrm{TiO}_{2}$ & 0,6 & 0,4 & 0,7 & 0,6 & 0,6 \\
\hline $\mathrm{Al}_{2} \mathrm{O}_{3}$ & 10,8 & 9,5 & 7,0 & 10,2 & 6,0 \\
\hline $\mathrm{Fe}_{2} \mathrm{O}_{3}$ & 41,5 & 60,4 & 44,9 & 44,7 & 54,5 \\
\hline $\mathrm{MgO}$ & 0,2 & 0,3 & 0,1 & 0,2 & 0,1 \\
\hline $\mathrm{CaO}$ & 0,0 & 0,0 & 0,0 & 0,0 & 0,0 \\
\hline $\mathrm{Na}_{2} \mathrm{O}$ & 0,1 & 0,0 & 0,0 & 0,1 & 0,0 \\
\hline $\mathrm{K}_{2} \mathrm{O}$ & 1,1 & 1,0 & 0,5 & 1,2 & 0,5 \\
\hline $\mathrm{MnO}$ & 0,0 & 0,0 & 0,1 & 0,3 & 0,1 \\
\hline $\mathrm{P}_{2} \mathrm{O}_{5}$ & 0,3 & 1,4 & 0,7 & 0,3 & 2,0 \\
\hline $\mathrm{Cr}_{2} \mathrm{O}_{3}$ & 0,0 & 0,0 & 0,0 & 0,0 & 0,0 \\
\hline $\mathrm{PF}$ & 6,0 & 10,9 & 6,8 & 6,5 & 10,1 \\
\hline Total & 99,4 & 99,8 & 100,0 & 99,9 & 99,8 \\
\hline $\mathrm{La}$ & 21,4 & 19,9 & 27,6 & 24,3 & 48,8 \\
\hline $\mathrm{Ce}$ & 39,9 & 35,7 & 67,9 & 44,9 & 151,7 \\
\hline $\mathrm{Pr}$ & 4,4 & 4,7 & 6,4 & 5,1 & 13,9 \\
\hline $\mathrm{Nd}$ & 15,7 & 18,3 & 21,4 & 19,7 & 51,0 \\
\hline $\mathrm{Sm}$ & 2,6 & 3,6 & 3,4 & 3,5 & 7,5 \\
\hline $\mathrm{Eu}$ & 0,6 & 0,8 & 0,7 & 0,8 & 1,4 \\
\hline $\mathrm{Gd}$ & 2,5 & 4,1 & 3,1 & 3,4 & 5,1 \\
\hline $\mathrm{Tb}$ & 0,5 & 0,7 & 0,6 & 0,6 & 0,9 \\
\hline Dy & 3,5 & 3,5 & 4,2 & 3,6 & 5,0 \\
\hline Ho & 0,7 & 0,9 & 0,8 & 0,8 & 1,0 \\
\hline $\mathrm{Er}$ & 2,7 & 2,6 & 2,8 & 2,5 & 3,1 \\
\hline $\mathrm{Tm}$ & 0,4 & 0,4 & 0,4 & 0,4 & 0,5 \\
\hline $\mathrm{Yb}$ & 2,7 & 2,2 & 3,1 & 2,5 & 3,0 \\
\hline $\mathrm{Lu}$ & 0,4 & 0,3 & 0,4 & 0,4 & 0,4 \\
\hline$\Sigma_{\mathrm{ETR}}$ & 98,0 & 97,8 & 142,7 & 112,4 & 293,3 \\
\hline $\mathrm{Ba}$ & 234,0 & 166,0 & 191,0 & 347,0 & 257,0 \\
\hline $\mathrm{Sr}$ & 40,6 & 31,5 & 34,5 & 44,9 & 51,3 \\
\hline $\mathrm{Rb}$ & 56,4 & 60,0 & 26,3 & 61,6 & 28,5 \\
\hline $\mathrm{Zr}$ & 111,7 & 62,2 & 371,5 & 118,3 & 279,3 \\
\hline $\mathrm{Y}$ & 23,4 & 24,8 & 22,1 & 22,8 & 27,6 \\
\hline $\mathrm{Nb}$ & 12,5 & 7,3 & 14,8 & 12,5 & 12,6 \\
\hline $\mathrm{Ga}$ & 16,4 & 11,8 & 8,9 & 15,6 & 9,0 \\
\hline Th & 10,8 & 7,6 & 11,1 & 10,5 & 9,4 \\
\hline $\mathrm{Hf}$ & 3,5 & 1,8 & 9,9 & 3,3 & 7,9 \\
\hline $\mathrm{Ta}$ & 0,8 & 0,5 & 1,2 & 0,7 & 1,0 \\
\hline $\mathrm{Ni}$ & 20,0 & 161,0 & 60,0 & 20,0 & 55,0 \\
\hline $\mathrm{Cr}$ & 120 & 80 & 90 & 60 & 70 \\
\hline Cs & 5,5 & 6,1 & 2,9 & 6,3 & 4,6 \\
\hline $\mathrm{V}$ & $3.488,0$ & 83,0 & 198,0 & 314,0 & 308,0 \\
\hline $\mathrm{U}$ & 2,7 & 1,9 & 3,9 & 2,1 & 2,9 \\
\hline Mo & 3,7 & 2,6 & 1,0 & 1,0 & 1,5 \\
\hline $\mathrm{Cu}$ & 5,6 & 31,7 & 8,8 & 6,9 & 28,8 \\
\hline $\mathrm{Pb}$ & 7,1 & 9,1 & 7,0 & 5,1 & 11,3 \\
\hline $\mathrm{Zn}$ & 25,0 & 868,0 & 63,0 & 19,0 & 139,0 \\
\hline $\mathrm{Bi}$ & 0,3 & 0,2 & 0,2 & 0,2 & 0,2 \\
\hline $\mathrm{Au}$ & 1,0 & 2,8 & 0,9 & 14,8 & 3,8 \\
\hline As & 410,5 & 4,3 & 177,5 & 141,5 & 201,6 \\
\hline $\mathrm{Be}$ & 2,0 & 4,0 & 3,0 & 3,0 & 5,0 \\
\hline Co & 4,2 & 21,3 & 32,4 & 25,0 & 26,9 \\
\hline $\mathrm{W}$ & 5,2 & 1,5 & 21,2 & 2,5 & 12,6 \\
\hline $\mathrm{Sc}$ & 19 & 10 & 10 & 12 & 8 \\
\hline
\end{tabular}


$\mathrm{Nd}>>\mathrm{Sm}, \mathrm{Pr}, \mathrm{Gd}>\mathrm{Dy}, \mathrm{Er} . . .$, com razões variadas de $\mathrm{Ce} / \mathrm{La}(1,84$ a 3,58$), \mathrm{Ce} / \mathrm{Nd}(1,74$ a 3,97$)$ e $\mathrm{La} / \mathrm{Nd}$ $(0,61$ a 2,15$)$. A soma dos ETR $\left(\Sigma_{\text {ETR }}\right)$ varia dentro de grande intervalo (144 a 1.630 ppm), com valor médio de $690 \mathrm{ppm}$.

\section{IRONSTONES NÃO OOLÍTICOS No per-}

fil Colinas do Tocantins-Couto Magalhães, somente foram identificados ironstones sem textura oolítica, que constituem leitos maciços com 1,5 a $2 \mathrm{~m}$ de espessura, interacamados com rochas sedimentares clásticas.

\section{Composição mineralógica}

Do ponto de vista mineralógico, a composição dos ironstones não oolíticos é muito similar à dos de Xambioá-Vanderlândia, embora aqueles sejam bem mais ricos em quartzo e, por via de consequência, mais pobres em goethita/hematita do que estes. Ocorrem, também, grãos detríticos de mica, monazita e zircão, aleatoriamente distribuídos.

Os grãos de quartzo são angulosos e arredondados a subarredondados. Os primeiros mostram tamanho de 0,02 a $0,25 \mathrm{~mm}$, bordas corroídas e, de modo geral, representam a maior parte da fração clástica das amostras. O segundo grupo apresenta tamanho entre 0,1 e 1,6 mm e, a eles, juntam-se, localmente, grãos angulosos com dimensões em torno de $1 \mathrm{~mm}$. A maioria mostra-se fraturada e com extinção ondulante.

As lamelas de mica (muscovita?), com dimensões de 0,1 a $0,4 \mathrm{~mm}$ e em quantidade bem inferior ao quartzo, apresentam aspecto degradado. Os grãos de monazita são angulosos a subarredondados, fraturados, com tamanhos entre 0,1 e $0,5 \mathrm{~mm}$ (Fig. 5A), e mais abundantes que os de zircão, os quais mostram dimensões entre 0,05 e $0,25 \mathrm{~mm}$ e formas que variam de arredondadas a angulosas, com raros cristais prismáticos piramidais.

A massa ferruginosa é relativamente homogênea e basicamente constituída por hematita e goethita. Em algumas amostras, observa-se sequência rítmica de laminações finas (Fig. 5B), caracterizada pela alternância das cores amarelo (rica em goethita) e vermelho (rica em hematita). Nem sempre, entretanto, essa alternância é evidente e a coloração tende a negra com pontos vermelhos esparsos. Muito localmente, a quantidade de clastos supera o material ferruginoso que, então, funciona como verdadeiro cimento. Esses clastos também se concentram em microleitos (amostra GL11, por exemplo) de coloração esbranquiçada, em que grãos de quartzo mostram tamanhos entre 0,01 e $0,05 \mathrm{~mm}$, e definem uma laminação plano-paralela fina marcada pela alternância com material hematítico-goethítico.

Composição química Os ironstones não oolíticos são constituídos, predominantemente, por $\mathrm{SiO}_{2} \mathrm{e} \mathrm{Fe}_{2} \mathrm{O}_{3}$ (todo $\mathrm{Fe}$ como $\mathrm{Fe}^{+3}$ ), que totalizam 76 a $84 \%$ do peso da rocha, sendo $\mathrm{Fe}_{2} \mathrm{O}_{3}(41,5$ a $60,4 \%)$ até quase quatro vezes maior do que $\mathrm{SiO}_{2}(15,85$ a 39,13\%). Além de $\mathrm{H}_{2} \mathrm{O}$, registrada como perda ao fogo (6 a 10,9\%), outro componente de maior expressão é o $\mathrm{Al}_{2} \mathrm{O}_{3}$, cujos teores cobrem a faixa de 6 a 10,8\% (Tab. 2). Seguem $\mathrm{K}_{2} \mathrm{O}$ e $\mathrm{P}_{2} \mathrm{O}_{5}$, os quais estão presentes com concentrações, que, em geral, não ultrapassam $1,4 \%$, embora $\mathrm{P}_{2} \mathrm{O}_{5}$ chegue a atingir $2 \%$. Os demais componentes registram valores inferiores a $0,1 \%$.

Dentre os elementos traços (Tab. 2), aqueles que mostram conteúdos médios mais significativos são V (878 ppm), Zr (189 ppm) e Ba (239 ppm), seguidos de $\mathrm{Rb}$ (47 pm), Ni (46 ppm) e $\mathrm{Sr}$ (41 pm). Th e Ga estão abaixo de 15 ppm e U registra apenas 3 ppm.

Com referência aos ETR, a $\Sigma_{\text {ETR }}$ varia de 100 a $300 \mathrm{ppm}$ (Tab. 2), com algum destaque para as ETRL, cujas concentrações apontam $\mathrm{Ce}>>\mathrm{La}>\mathrm{Nd}$ e razões $\mathrm{Ce} / \mathrm{La}(1,79$ a 3,11$)$ e $\mathrm{Ce} / \mathrm{Nd}(1,95$ a 3,17$)$ mais variáveis do que as de $\mathrm{La} / \mathrm{Nd}(0,96$ a 1,36). As demais ETR estão, em geral, abaixo de 5 ppm.

\section{DISCUSSÃO}

\section{Fonte dos sedimentos dos ironstones estudados}

Os dados petrográficos e de MEV-EDS mostram que, na formação dos ironstones de ambos os perfis, houve tanto contribuição detrítica como química, significando que, além da precipitação marinha, foram aportados para a bacia, ainda que em menores proporções, produtos da erosão continental.

\section{SEDIMENTOS DETRÍTICOS Como registrado,} o material detrítico é representado, principalmente, por quartzo, zircão, monazita, micas, argilominerais e goiasita, nem todos, entretanto, reconhecidos nas duas variedades de ironstones estudadas. As áreasfontes foram, provavelmente, rochas do embasamento e do Cinturão Araguaia. Por ser mineral comumente formado em ambiente supergênico, a presença de goiasita pode indicar derivação de alguma cobertura 
Tabela 3 - Estimativas das proporções de argilominerais e quartzo (\% peso), baseadas em dados de composição química (MEV-EDS) em ironstones ooliticos

\begin{tabular}{|c|c|c|c|c|c|c|c|c|c|c|c|c|c|}
\hline Minerais & GL-01 & GL-02 & GL-07 & BA-02a & BA-03 & BA-04 & BA- 05 & GL-52a & GL-52b & GL-53a & GL-53b & GL-53c & GL-53d \\
\hline Argilominerais & 3,1 & 3,6 & 3,9 & 0,0 & 10,6 & 3,3 & 0,0 & 2,9 & 3,7 & 3,1 & 6,6 & 6,8 & 0,0 \\
\hline Quartzo & 11,2 & 11,4 & 12,6 & 3,0 & 10,4 & 13,8 & 2,8 & 4,8 & 10,5 & 5,7 & 8,1 & 9,9 & 3,3 \\
\hline
\end{tabular}
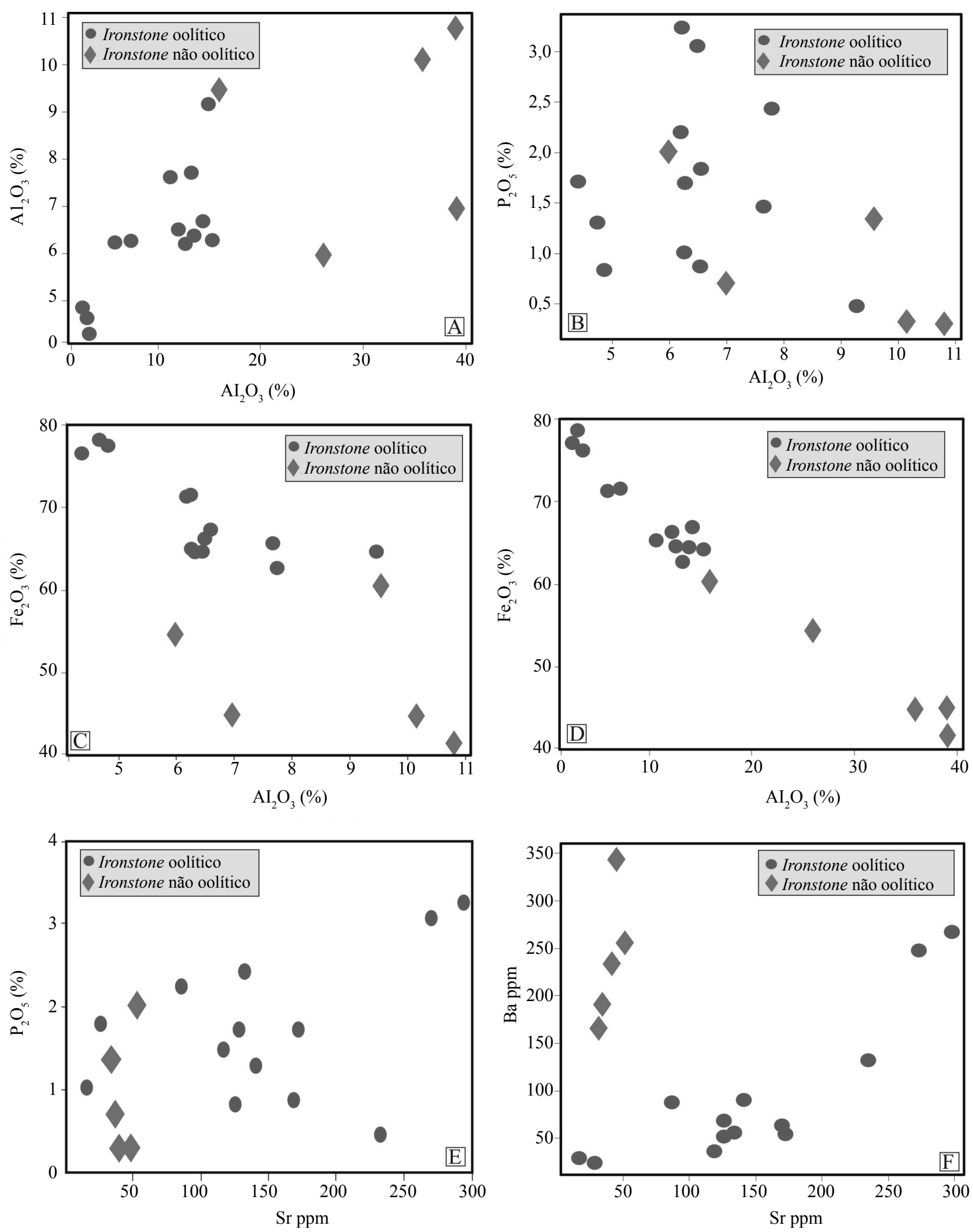

Figura 6 - Diagramas de correlação entre componentes maiores elou elementos traços para os ironstones ooliticos e não oolíticos. (A) $\mathrm{Al}_{2} \mathrm{O}_{3}$ versus $\mathrm{SiO}_{2}$; (B) $\mathrm{P}_{2} \mathrm{O}_{5}$ versus $\mathrm{Al}_{2} \mathrm{O}_{3}$; (C) $\mathrm{Fe}_{2} \mathrm{O}_{3}$ versus $\mathrm{Al}_{2} \mathrm{O}_{3}$; (D) $\mathrm{Fe}_{2} \mathrm{O}_{3}$ versus $\mathrm{SiO}_{2}$; (E) $\mathrm{P}_{2} \mathrm{O}_{5}$ versus $\mathrm{Sr}$ e (F) Ba versus $\mathrm{Sr}$. 
laterítica que teria sido desmantelada em períodos pré-devonianos. É possível, também, que raros fragmentos de oólitos possam provir dessa mesma cobertura.

Não foram realizadas análises modais dos ironstones, porém pôde-se inferir, com base nos dados petrográficos e químicos, que os oxi-hidróxidos de ferro dos ironstones oolíticos constituem pelo menos $80 \%$ do volume dessas rochas. Ademais, considerando as análises semiquantitativas da esmectita/caulinita (médias de $40 \%$ de $\mathrm{Al}_{2} \mathrm{O}_{3}$ e $45 \%$ de $\mathrm{SiO}_{2}$ ) e Al-goethita (média de 6,5\% de $\mathrm{Al}_{2} \mathrm{O}_{3}$ ), obtidas por MEV-EDS, bem como o fato de que a alumina restante deve-se às quantidades destes argilominerais, chega-se a estimativas de 0 até $10 \%$ para a esmectita/caulinita e de 5 até $14 \%$ para quartzo nesses ironstones (Tab. 3).

Pode-se, assim, concluir que, independentemente da fonte, pouco material detrítico $(<15 \%)$ foi aportado aos sítios onde se depositaram os ironstones, ainda que, na região de Colinas do Tocantins-Couto Magalhães, tenha havido maior contribuição clástica, notadamente de quartzo $(>20 \%)$.

\section{SEDIMENTOS QUIMMICOS As evidências apre-} sentadas permitem sustentar que os ironstones devem ter sido formados por processos francamente químicos. A questão principal está centrada em torno da fonte e do transporte do ferro que veio a ser depositado como goethita e hematita (cimento e os próprios oólitos). Sem registro de vulcanismo na área estudada em tempos paleozoicos, descartou-se a existência de fonte vulcânica e/ou hidrotermal e, como alternativa, foram apontadas condições climáticas e físicoquímicas especiais, capazes de solubilizar o ferro a partir de minerais preexistentes e mobilizá-lo até os sítios deposicionais, o que será discutido no modelo de formação dos ironstones.

\section{Assinaturas geoquímicas}

IRONSTONES OOLÍTICOS Os teores de $\mathrm{SiO}_{2}$ e $\mathrm{Al}_{2} \mathrm{O}_{3}$ das amostras oolíticas revelam correlação positiva (Fig. 6A), o que deve ser, em grande parte, controlada pela abundância de argilominerais. Algumas amostras encontram-se deslocadas para a direita, denunciando certamente maiores proporções de quartzo. No gráfico $\mathrm{P}_{2} \mathrm{O}_{5} \times \mathrm{Al}_{2} \mathrm{O}_{3}$ (Fig. 6B), a distribuição dos pontos é errática, embora alguns deles exibam discreta correlação positiva. Essa tendência poderia, pelo menos em parte, ser resultado do aporte concomitante de fostatos e argilominerais como materiais detríticos à bacia de deposição. Acontece, porém, que há muito mais $\mathrm{P}_{2} \mathrm{O}_{5}$ nos ironstones do que poderia ser fornecido pela monazita e goiasita neles presentes. Mesmo que a proporção modal destes minerais fosse $1 \%$, o que estaria evidentemente superestimado, eles contribuiriam com, no máximo, em torno de $0,4 \%$ de $\mathrm{P}_{2} \mathrm{O}_{5}$ para aquelas rochas, valor bem inferior aos teores obtidos (Tab. 1). Dessa forma, aparentemente, a principal fonte de fósforo nos ironstones provém da adsorção nos oxi-hidróxidos de Fe (Lijklema 1980, Sanyal \& De Datta 1991, Piasecki \& Sverjensky 2008).
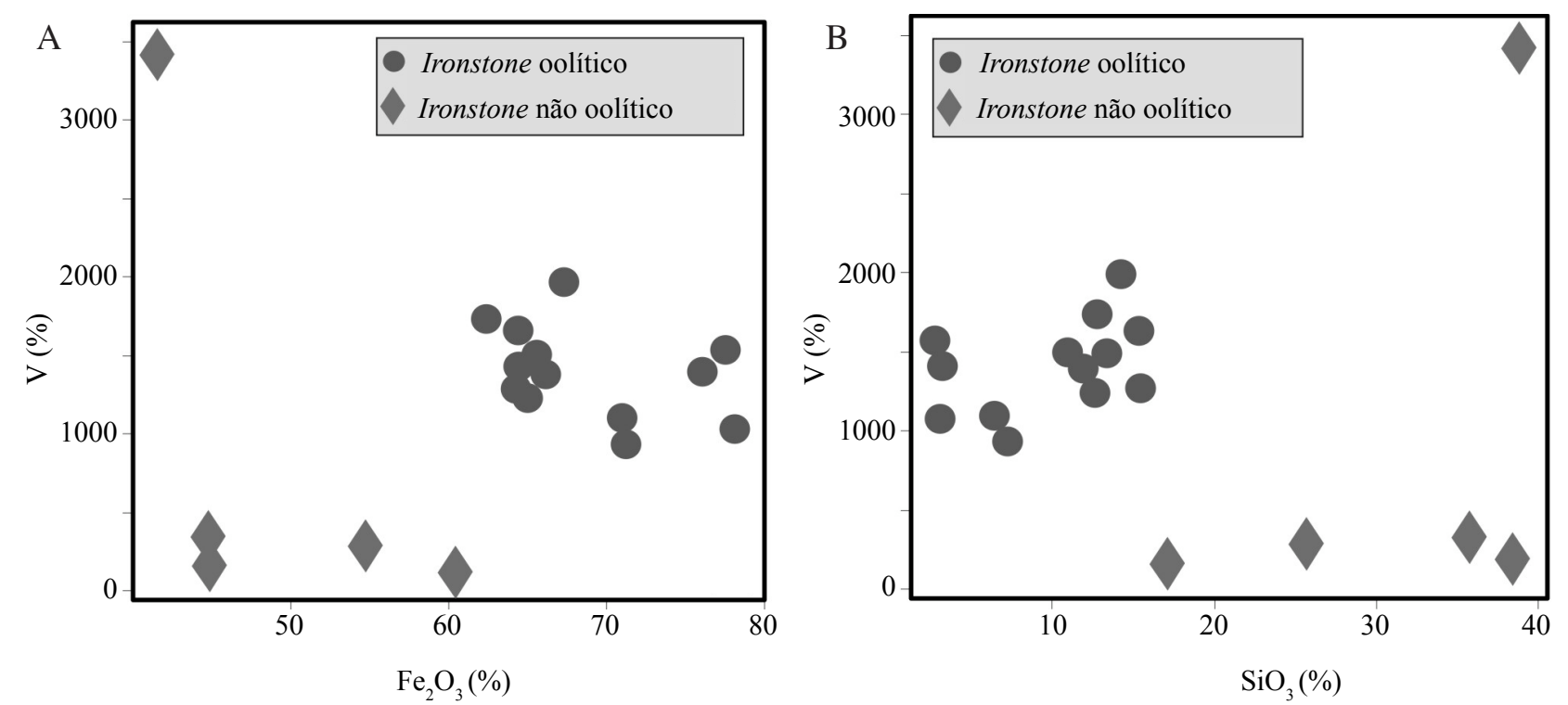

Figura 7 - Diagramas binários V versus $\mathrm{Fe}_{2} \mathrm{O}_{3}(\mathrm{~A})$ e V versus $\mathrm{SiO}_{2}(\mathrm{~B})$ para amostras de ironstone oolítico. 
Confrontando-se o $\mathrm{Fe}_{2} \mathrm{O}_{3}$ com o $\mathrm{Al}_{2} \mathrm{O}_{3}$ (Fig. 6C) e com o $\mathrm{SiO}_{2}$ (Fig. 6D), observa-se correlação negativa em ambos os casos, embora bem mais evidente e acentuada com o $\mathrm{SiO}_{2}$.

A mais importante fonte de Sr é a goiasita detrítica. A relação com o $\mathrm{P}_{2} \mathrm{O}_{5}$ é pobremente definida (Fig. 6E), talvez pelo fato de os teores de $\mathrm{P}$ resultarem muito mais de adsorção. Duas amostras (GL-01 e GL-02) acusam os teores mais elevados de $\mathrm{Sr}(296$ e $271 \mathrm{ppm}$ ) e de $\mathrm{P}_{2} \mathrm{O}_{5}$ (3,25 e 3,07\%), o que pode significar que, nelas, a goiasita é mais abundante, mas não em proporções suficientes para responder pelos altos teores de $\mathrm{P}$.

Os teores de $\mathrm{V}$ variam discretamente com o aumento das concentrações de Fe e de sílica, havendo relação antipatética com o primeiro (Fig. 7A) e simpatética com $\mathrm{SiO}_{2}$ (Fig. 7B). O vanádio é elemento de grande mobilidade em ambiente sedimentar, onde é concentrado subeconomicamente em depósitos de U-Cu-V em arenitos, por exemplo. No caso dos ironstones da Formação Pimenteiras, é possível que o $\mathrm{V}$ faça parte da estrutura de algum argilomineral, do tipo interestratificado, ou esteja adsorvido em oxi-hidróxidos de Fe (Peacock \& Sherman 2004). Estudos experimentais mostram que a adsorção de $\mathrm{V}^{+5}$ em goethita, sob condições atmosféricas, é favorecida na faixa de $\mathrm{pH}$ entre 6 e 9 , desde que $[\mathrm{V}]_{\text {total }}$ em solução seja superior a 2,5 ppm (Schwertmann \& Pfab 1996). Contudo, se a adsorção tivesse prevalecido, era de se esperar correlação positiva entre $\mathrm{Fe} e \mathrm{~V}$, o que não se observou. Similarmente, U pode ser adsorvido como íons uranil, sendo os oxi-hidróxidos de $\mathrm{Fe}$ um dos principais adsorventes (Nash et al. 1981).

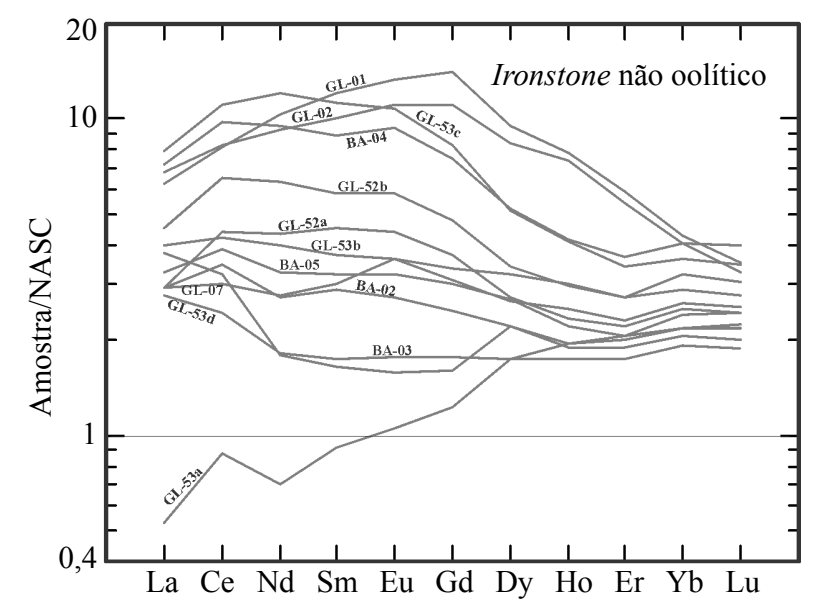

Figura 8 - Padrões de distribuição dos ETR de amostras de ironstone oolítico (região de XambioáVanderlândia) normalizados ao NASC.
Quantidades de 0,02 a $0,12 \%$ são estimativas bem plausíveis para a quantidade de zircão $(\mathrm{Zr}=52$ a $57 \%$; Hf $=1,6$ a 2,4\%) presente nos ironstones e, assim, respondem plenamente pelos teores de $\mathrm{Zr}$ detectados nestas rochas, bem como pelos de Hf. Semelhantes quantidades modais de monazita $(\mathrm{Th}=5,6 \%)$ e de goiasita $(\mathrm{Sr} \approx 11 \%)$ seriam suficientes para dar conta dos teores de $\mathrm{Th}$ e $\mathrm{Sr}$ nos ironstones. Considerando-se que o $\mathrm{Ba}$ comumente substitui o $\mathrm{Sr}$ na estrutura da goiasita, poder-seia atribuir também a este mineral os teores de $\mathrm{Ba}$ determinados nos ironstones. Significativamente, os teores destes dois elementos guardam forte correlação positiva (Fig. 6F). Face à grande afinidade geoquímica com o $\mathrm{Al}$, os teores de $\mathrm{Al}_{2} \mathrm{O}_{3}$ (média de $6,35 \%$ ) são mais do que suficientes para justificar as concentrações de Ga que foram dosadas. Mais problemática seria a explicação para os moderados conteúdos de $\mathrm{Ni}$, porém rochas máfico-ultramáficas, de comum ocorrência no cinturão Araguaia, poderiam ser a fonte deste metal nos sedimentos que foram aportados à bacia do Parnaíba.

Importante fonte dos ETR nesses ironstones é a monazita detrítica, para a qual análises semiquantitativas forneceram teores médios de 28,2\% (Ce), $10,4 \%(\mathrm{La})$ e $9,6 \%(\mathrm{Nd})$, bem como razões $\mathrm{Ce} / \mathrm{La}$ $(2,70), \mathrm{Ce} / \mathrm{Nd}(2,93)$ e $\mathrm{La} / \mathrm{Nd}(1,08)$. Bastariam quantidades de até $0,25 \%$ de monazita para justificar os teores de ETR detectados nessas rochas (Tab. 1). $\mathrm{Se}$, entretanto, este valor for superestimado, parte dos ETR pode ser devida à adsorção (Sturesson 1995, Piasecki \& Sverjensky 2008).

Quando normalizadas ao North American Shale Composite - NASC (Gromet et al. 1984), as amostras de ironstone oolítico mostram-se mais enriquecidas nestes elementos do que este padrão (Fig. 8). Excetua-se, em parte, a amostra GL-53A, na qual La, $\mathrm{Ce}, \mathrm{Nd}$ e Sm são mais empobrecidos. Não há uniformidade no padrão de distribuição dos ETR, observando-se, ademais, modestas anomalias positivas de $\mathrm{Ce}$ em algumas amostras. Em contrapartida, apenas uma anomalia, também positiva de Eu, destaca-se na porção mediana do gráfico.

O comportamento de parte das amostras revela evidente convexidade com enriquecimento discreto dos ETRL em relação aos ETRI, especialmente a partir do Gd, que se acentua, porém, em relação aos ETRP. Duas amostras, em particular, exibem enriquecimento das ETRI relativamente tanto aos ETRL como aos ETRP, constatando-se, em ambas, os mais 
elevados valores de $\mathrm{Gd}_{\mathrm{N}}$, os quais permitem dividir as curvas em dois segmentos distintos: um crescente de $\mathrm{La}_{\mathrm{N}}$ para $\mathrm{Gd}_{\mathrm{N}}$ e outro decrescente de $\mathrm{Gd}_{\mathrm{N}}$ para $\mathrm{Lu}_{\mathrm{N}}$. Esse comportamento convexo deve ser, pelo menos em parte, controlado pela abundância de monazita $(\Sigma$ ETRL $=46 \% ; \Sigma$ ETRI $=1,5 \% ; \Sigma$ ETRP $=3,8 \%)$ e de zircão ( $\Sigma$ ETRL $=1,1 \%$; $\Sigma$ ETRI $=2,2 \%$; $\Sigma$ ETRP $=1,2 \%$ ). Em outras amostras, o comportamento tende à sub-horizontalidade com enriquecimento sutil dos ETRL ou ETRI em relação aos ETRP e há, até mesmo, contrariamente, enriquecimento dos ETRP em relação aos ETRL em uma amostra (GL-53a), denunciando escassez de monazita e distribuição dos ETR controlados, essencialmente, pelo zircão. Entretanto, como não foi possível avaliar a que extensão se deu a possível adsorção dos ETR nos oxi-hidróxidos de Fe, reconhece-se a dificuldade em atribuir somente à monazita e ao zircão o comportamento destes elementos nas amostras dos ironstones oolíticos. Ressalta-se, não obstante, que a forma convexa é típica dos fosfatos antigos e parece ser produzida quando ETR adsorvidos pelos oxi-hidróxidos de ferro são transferidos para fases fosfáticas durante os estágios iniciais da diagênese (Grandjean-Lécuyer et al. 1993).

\section{Ironstones não oolíticos}

Nas amostras dos ironstones não oolíticos, por um lado, os elevados teores de $\mathrm{Fe}_{2} \mathrm{O}_{3}$ e $\mathrm{SiO}_{2}$ refletem as quantidades de oxi-hidróxidos de $\mathrm{Fe}$ e de silicatos, respectivamente, observando-se relação inversa entre estes dois componentes (Fig. 6D). Por outro lado, como as proporções de quartzo e argilominerais são muito variáveis,

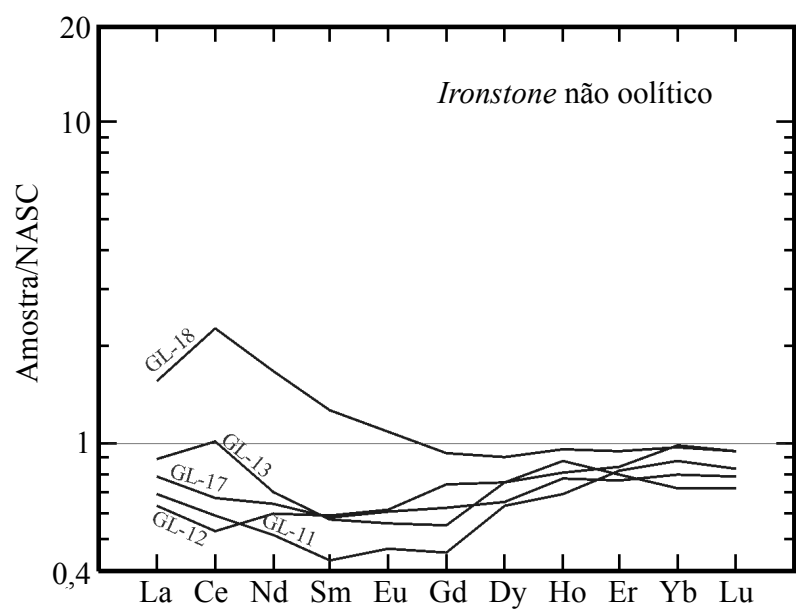

Figura 9-Padrão de distribuição dos ETR em amostras de ironstone não oolítico (região de Colinas do Tocantins-Couto Magalhães) normalizados ao NASC. a correlação entre $\mathrm{SiO}_{2} \mathrm{e}_{2} \mathrm{O}_{3}$ é, de certa forma, aleatória (Fig. 6A), embora perceba-se que amostras com maiores teores de $\mathrm{SiO}_{2}$ tendam a apresentar os mais elevados teores de $\mathrm{Al}_{2} \mathrm{O}_{3}$ e, contrariamente, aquelas com menores teores de $\mathrm{Al}_{2} \mathrm{O}_{3}$, em que os argilominerais são menos abundantes, tendam a apresentar os maiores teores de $\mathrm{Fe}_{2} \mathrm{O}_{3}$ (Fig. 6C). Em decorrência, as amostras mais ricas em $\mathrm{Al}_{2} \mathrm{O}_{3}$ são mais pobres em $\mathrm{P}_{2} \mathrm{O}_{5}$ (Fig. 6B), o que provavelmente indica o menor teor de fósforo adsorvido nas amostras mais pobres em oxi-hidróxidos de ferro, ou seja, mais ricas em argilominerais. Por seu turno, a presença de mica branca detrítica no arcabouço mineralógico desses ironstones responde possivelmente pelo teor médio de $\mathrm{K}_{2} \mathrm{O}$, em torno de $0,9 \%$.

A presença de grãos de zircão e de palhetas de mica branca, mesmo em pequenas quantidades, pode justificar plenamente as concentrações de $\mathrm{Zr}$ e $\mathrm{Rb}$, enquanto que as de $\mathrm{Sr}$ podem ser devido a conteúdos subordinados de goiasita. Os elevados teores de V sugerem a ocorrência de argilominerais interestratificados, em especial na amostra GL-11, na qual alcançam quase $3.500 \mathrm{ppm}$, sem que se possam descartar as contribuições devido ao fenômeno da adsorção em oxi-hidróxidos de Fe (Schwertmann \& Pfab 1996, Peacock \& Sherman 2004). Outra possibilidade que poderia justificar as altas concentrações de vanádio nos ironstones e, por extensão, também as de $\mathrm{Ba}$, seria a substituição destes elementos nas micas, entrando, respectivamente, nos sítios do $\mathrm{Al}^{\mathrm{VI}}$ e $\mathrm{K}$ (Lee \& Lee 2003). Privilegia-se esta alternativa, pois, como os teores de Ba são de cinco a oito vezes maiores do que os de $\mathrm{Sr}$ e não há correlação positiva entre eles (Fig. 6F), não se pode creditar à goiasita os valores anômalos de Ba. A erosão das extensas ocorrências de rochas máficas no Grupo Tocantins poderia responder, em parte, pelas elevadas concentrações de $\mathrm{Ni}$ observadas nos ironstones.

Padrões dos ETR das amostras de ironstone não oolítico, também normalizadas ao NASC, são apresentados na Fig. 9. A mais marcante característica é o empobrecimento das ETR em relação ao NASC, com exceção da parte relativa aos ETRL da amostra GL-18. Outra característica é a forma côncava do padrão de quatro amostras dada pelo fracionamento, ainda que fraco, dos ETRL em relação aos ETRI e pela sub-horizontalidade a partir do Dy até o Lu. A amostra GL-18 revela padrão distinto, com leve fracionamento dos ETRL em relação aos ETRP e a mais acentuada anomalia positiva de Ce. 
Esse comportamento está em sintonia com as baixas quantidades de monazita e zircão nas amostras (exceto, talvez, a GL-18) e pode indicar fonte diversa para o material detrítico daquela que supriu o dos ironstones oolíticos.

\section{PRINCIPAIS DIFERENÇAS ENTRE OS} PERFIS ESTUDADOS Apesar de os ironstones estudados ocorrerem na porção basal da mesma unidade litoestratigráfica (Formação Pimenteiras), constatam-se importantes diferenças entre os perfis de Xambioá-Vanderlândia e de Colinas do TocantinsCouto Magalhães.

A diferença mais marcante reside na textura oolítica dos ironstones do perfil XambioáVanderlândia, textura esta não reconhecida nas amostras do outro perfil. Possivelmente, ambos os tipos de ironstones foram formados em plataforma aberta, porém, em Xambioá-Vanderlândia, as águas foram rasas e agitadas, propiciando o desenvolvimento dos oólitos. Essas condições não devem ter prevalecido na região de Colinas de Tocantins-Couto Magalhães, que é mais afastada da costa, onde a profundidade foi maior e as águas mais calmas.

Do ponto de vista mineralógico, ressaltase a maior abundância de quartzo e argilominerais nas amostras do perfil Colinas do Tocantins-Couto Magalhães, o que leva, consequentemente, a proporções menores de goethita nos ironstones não oolíticos. Com relação aos minerais pesados, grãos de zircão, de tipologia diversa, são muito mais comuns nos ironstones oolíticos e, muito provavelmente, são provenientes de fontes variadas. Por seu turno, a monazita ocorre na forma detrítica em ambos os perfis, porém somente no material oolítico foi identificada como precipitado químico, compondo camadas concêntricas de alguns oólitos. Ainda dentre os minerais pesados, destaca-se a ocorrência de goiazita unicamente nos ironstones oolíticos. Mica branca, na forma de ripas finas e bastante degradadas, foi observada somente nos ironstones não oolíticos.

Refletindo essas variações mineralógicas, observam-se importantes diferenças químicas nas amostras dos dois perfis. A mais marcante evidencia-se na Fig. 6D, que relaciona os teores de $\mathrm{SiO}_{2}$ e $\mathrm{Fe}_{2} \mathrm{O}_{3}$, com nítida separação entre as amostras dos ironstones oolíticos e não oolíticos, estes últimos mais ricos em sílica e mais empobrecidos em oxi-hidróxidos de $\mathrm{Fe}$. As linhas divisórias seriam em torno de 15\% de $\mathrm{SiO}_{2}$ ou $60 \%$ de $\mathrm{Fe}_{2} \mathrm{O}_{3}$. O $\mathrm{Al}_{2} \mathrm{O}_{3}$ tende a ser mais

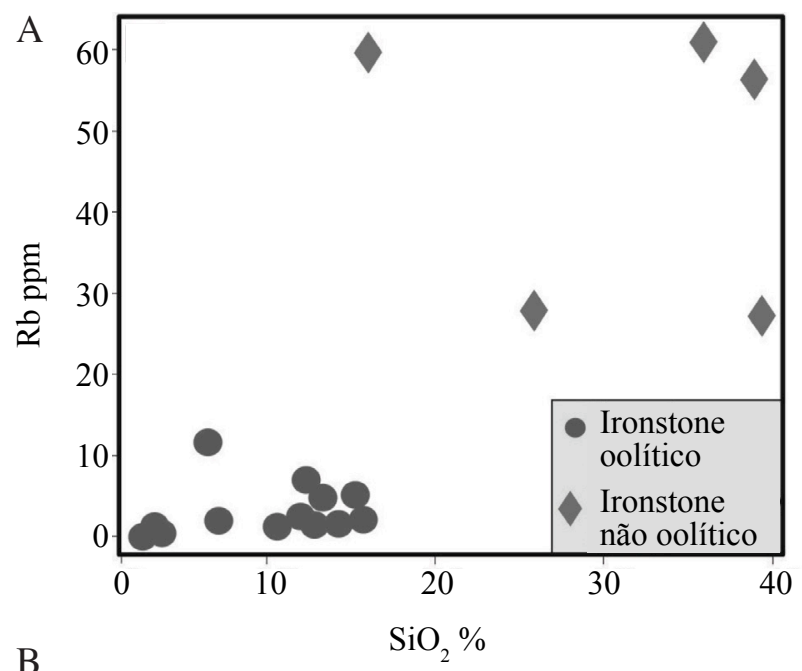

B
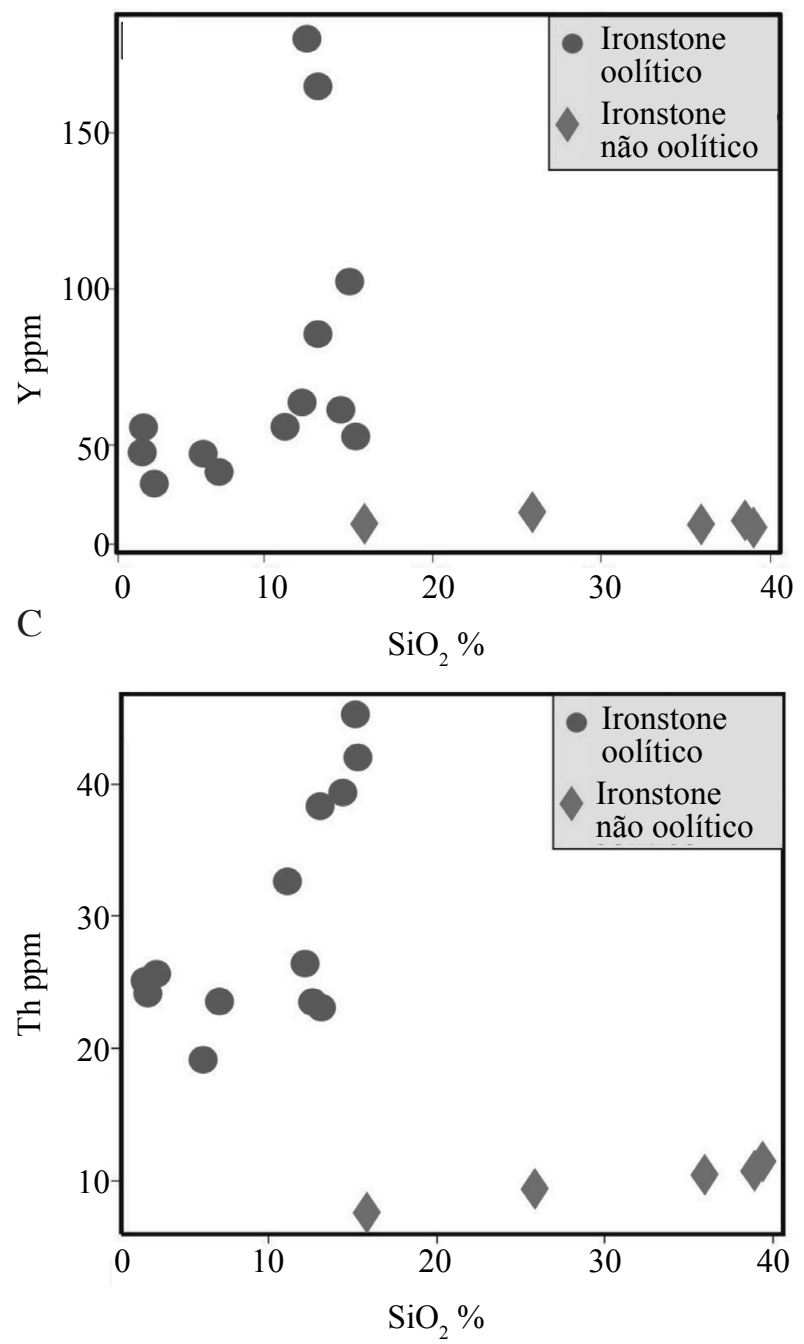

Figura 10 - Diagramas de correlação entre sílica e elementos traços selecionados para os ironstones oolíticos e não ooliticos. (A) $\mathrm{SiO}_{2}$ versus $\mathrm{Rb}$; (B) $\mathrm{SiO}_{2}$ versus The (C) $\mathrm{SiO}_{2}$ versus $\mathrm{Y}$.

enriquecido nas amostras dos ironstones não oolíti$\cos , 80 \%$ das quais registram valores $\geq 7 \%$. Igual percentual das amostras de ironstones oolíticos registra, 


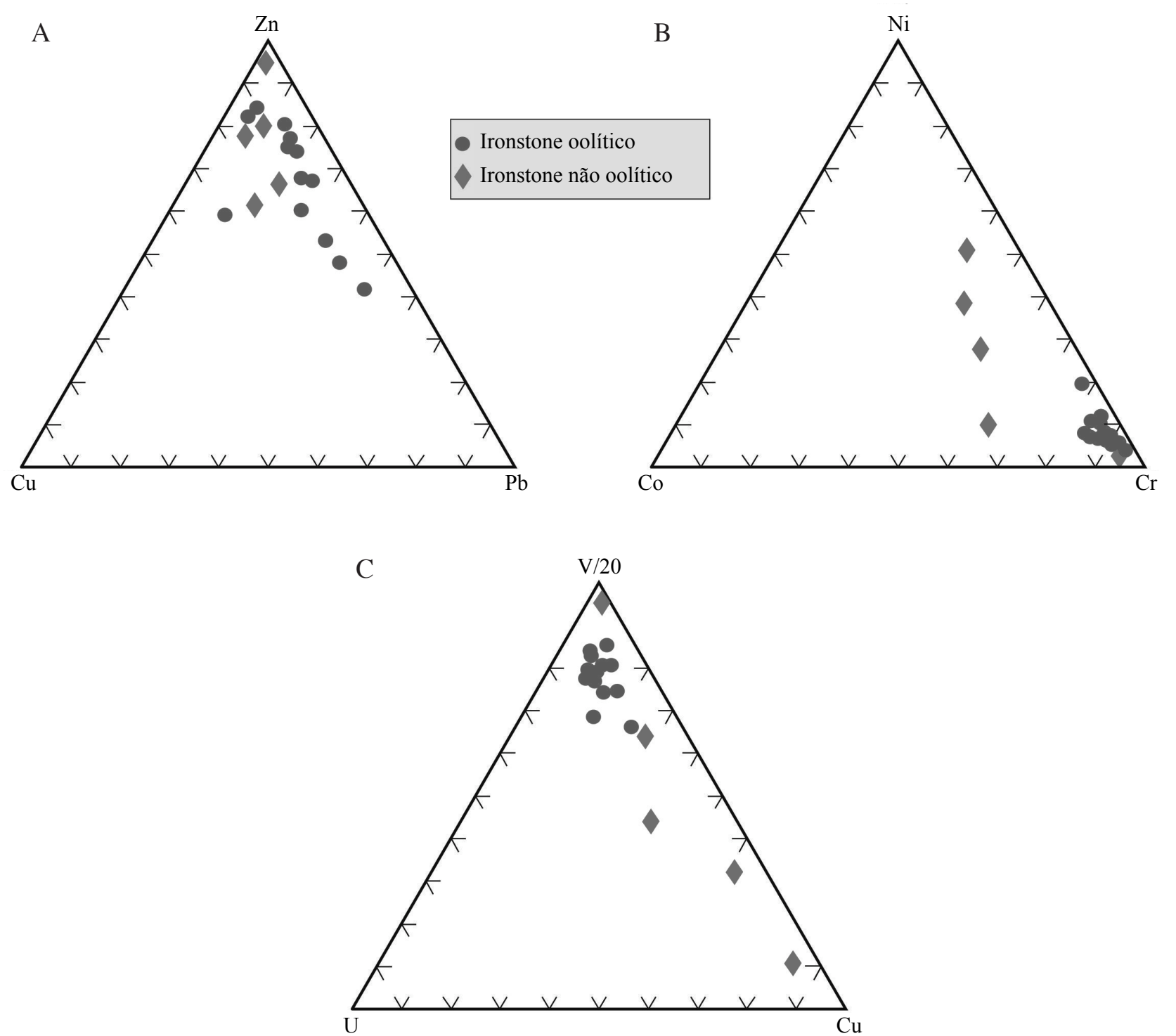

Figura 11 - Diagramas ternários utilizando-se $\mathrm{Zn}$, Cu e $\mathrm{Pb}$ (A), Ni, Co e Cr (B) e V/20, U e Cu (C) para comparação entre ironstones oolíticos e não oolíticos.

por outro lado, valores $<7 \%$ (Fig. 6A e 6C). Outra importante diferença reside no teor médio de $\mathrm{K}_{2} \mathrm{O}$, que é em torno de 15 vezes maior nas amostras dos ironstones não oolíticos $(0,88$ versus $0,06 \%)$, o que é, possivelmente, devido às maiores quantidades de mica branca e esmectita.

Quanto aos elementos traços, registra-se que o Rb é, em média, 15 vezes mais rico nas amostras do ironstone não oolítico, as quais podem ser separadas das oolíticas pela linha correspondente a $20 \mathrm{ppm}$ (Fig. 10A). Por seu turno, os teores médios de Y e Th são pelo menos três vezes mais elevados nas amostras de ironstone oolítico, cujos limites de 30 e $15 \mathrm{ppm}$ podem, respectivamente, discriminá-las das amostras não oolíticas (Fig. 10B e 10C). Ba e Sr também podem servir como critérios discriminantes para as amostras de ironstones oolíticos e não oolíticos, tanto pela presença e ausência de correlação, quanto pelo fato de $85 \%$ das primeiras se situarem à direita e abaixo das linhas divisórias de 50 ppm de $\mathrm{Sr}$ e de $150 \mathrm{ppm}$ de Ba, respectivamente (Fig. 6F).

Utilizando-se diagramas ternários, nenhuma distinção fica aparente com base nos metais-base $\mathrm{Cu}$, $\mathrm{Zn}$ e $\mathrm{Pb}$ (Fig. 11A), ao contrário dos diagramas NiCo-Cr (Fig. 11B) e V-U-Cu (Fig. 11C), os quais evidenciam a concentração das amostras dos ironstones oolíticos nos vértices representados pelo $\mathrm{Cr}$ e $\mathrm{V}$, enquanto a maioria das amostras dos ironstones nãooolíticos tende a deles se afastar, dispersando-se em direção aos lados Ni-Co e Cu-U.

Diferenças também se manifestam comparando-se os teores de ETR, que são, em média, aproximadamente 
5,5 vezes mais elevados nos ironstones oolíticos, os quais contêm maiores proporções não só de monazita e zircão como também de oxi-hidróxidos de Fe com capacidade, portanto, de adsorver maiores quantidades daqueles elementos. Além disso, em relação ao NASC, as amostras dos ironstones oolíticos são mais enriquecidas em ETR e as dos não oolíticos mais empobrecidas. Quanto ao padrão de distribuição desses elementos, a forma abaulada da maioria das amostras de ironstone oolítico está ausente nas amostras dos não oolíticos (Figs. 8 e 9). De outra feita, observam-se semelhanças de comportamento entre as amostras BA-03, GL-07, GL53b e GL-53d (oolíticas) e GL-11, GL-12, GL-13 e GL-17 (não oolíticas).

Em relação aos tipos clássicos Clinton e Minette, a diferença mais marcante, além da idade, reside na ausência de chamosita e de carbonatos nos ironstones estudados.

\section{MODELO GENÉTICO Como não há regis-} tro de atividade vulcânica ou exalativa nos tempos devonianos da evolução da Bacia do Parnaíba, o ferro dos ironstones da base da Formação Pimenteiras deve ter sido derivado da erosão continental, o que tem forte suporte na presença de minerais, que são, incontestavelmente, detríticos nessas rochas. Ademais, os teores bem elevados de ferro e a textura oolítica apontam para condições e ambientes muito particulares na geração desses ironstones.

O material detrítico resultou da decomposição de rochas pré-cambrianas do embasamento da Bacia do Parnaíba e que foram denudadas, predominantemente, por erosão fluvial. Mais questionáveis são a origem e a fonte do material químico, sobretudo o Fe. As altas quantidades de Fe dos ironstones exigiriam um reservatório, onde este elemento estivesse inicialmente concentrado para, sem segui$\mathrm{da}$, ser lenta e progressivamente liberado. Longo período de laterização poderia prover essa reserva de $\mathrm{Fe}$, o qual, mediante condições favoráveis, seria mobilizado até a bacia de deposição. A despeito de haver outras alternativas, como, por exemplo, a formação de crosta ferruginosa não laterítica sob clima temperado frio e condições podzolizantes, a presença de goiasita nos ironstones e o conteúdo de Al na goethita favorecem a hipótese de laterização das rochas-fonte. Ademais, as concentrações extremamente baixas de $\mathrm{Al}$ na água do mar corroboram a estreita ligação deste elemento com a hipotética cobertura laterítica. Semelhante argumento pode ser usado para alguns elementos traços. Uma vez desmantelada, fragmentos dessa cobertura teriam sido incorporados à carga de sedimentos dos rios. O difícil de explicar nesse cenário geral seriam mudanças tão radicais e relativamente rápidas de clima frio para tropical úmido.

$\mathrm{O} \mathrm{Fe}$ teria sido transportado em suspensão, na forma de coloides e de complexos orgânicos estáveis, em atmosfera oxidante. A formação desses complexos teria, entretanto, requerido acumulação de matéria orgânica em condições propícias a sua lenta degradação semelhantemente àquelas em que os bog irons são gerados. Ambientes pantanosos típicos dos bog irons podem ter se formado ao final da grande glaciação siluriana. Alternativamente, poder-se-ia supor a presença de ecossistemas lagunares, onde, em resposta à limitada circulação da água do mar e, consequentemente, à escassez de oxigênio, meios redutores poderiam ser desenvolvidos. Em ambas as situações, o transporte do Fe teria sido favorecido possivelmente pela formação de complexos húmicos e fúlvicos, que têm sido apontados como importantes supridores continentais deste metal aos reservatórios marinhos (Krachler et al. 2010).

Ao atingir o oceano, os sedimentos foram redistribuídos na plataforma continental, na qual o $\mathrm{Fe}^{+2}$ foi oxidado e precipitado fundamentalmente como goethita, formando uma massa ferruginosa que substituiu ou se misturou com o material pelítico da carga sedimentar. $\mathrm{O}$ carbono oriundo da desestabilização daqueles complexos orgânicos pode ter funcionado como o principal agente da oxidação. Em ambiente de águas agitadas, abundantes centros de nucleação da goethita favoreceram a geração de oólitos, muitos dos quais cresceram incorporando grãos detríticos em seus núcleos. Processos diagenéticos subsequentes deram origem aos ironstones oolíticos, como os que ocorrem na região de Xambioá-Vanderlândia. Em outros sítios, de águas mais calmas e profundas, a deposição química do hidróxido de ferro parece ter ocorrido a uma taxa comparável à do material detrítico, inibindo-se a formação de oólitos. Os ironstones resultantes mostram textura não oolítica, como aqueles que afloram na região de Colinas do TocantinsCouto Magalhães.

É provável que a hematita encontrada em ambas as variedades de ironstones decorra da desidratação de parte da goethita em algum estágio da evolução diagenética dessas rochas. Entretanto, o $\mathrm{pH}$ e a temperatura das águas marinhas à época 
parecem ter sido inadequados para promover a dissolução, ainda que parcial, dos grãos detríticos de quartzo, não tendo havido, por conseguinte, liberação de sílica necessária à formação da chamosita, como a que foi identificada em ironstones da porção mais ao sul do estado do Tocantins, também na base da Formação Pimenteiras (Ribeiro \& Dardenne 1978).

\section{Referências}

Aguiar G.A. 1971. Revisão geológica da bacia paleozóica do Maranhão. In: SBG, Congresso Brasileiro de Geologia, XXV, Anais, v.3, p.113-122.

Amaro G.J.L. 1985. Estudos das ocorrências ferromanganesíferas na interface Proterozóico Superior (Formação Xambioá) e Paleozóico (Formação Pimenteiras). Trabalho de Conclusão de Curso, Departamento de Geologia, Universidade Federal do Pará, Belém, $18 \mathrm{p}$.

Ambrosi J. P. \& Nahon D. 1986. Petrological and geochemical differentiation of lateritic iron crust profiles. Chemical Geology, 57:371-393.

Bekker A., Slack J.F., Planavsky N., Krapez B., Hofmann A., Konhauser K.O., Rouxel O.J. 2010. Iron Formation: the sedimentary product of a complex interplay among mantle, tectonic, oceanic, and biosphere processes. Econonic Geology, 105:467-508.

Blanch A.J., Quinton J.S., Lenehan C.E., Pring A. 2008. The crystal chemistry of Al-bearing goethites: an infrared spectroscopic study. Mineralogical Magazine, 72:1043-1056.

Byrne R.H. \& Kim K. 1990. Rare earth element scavenging in seawater. Geochimica et Cosmochimica Acta, 54:2645-2656.

Dardenne M.A. \& Schobenhaus C. 2001. Metalogênese do Brasil. CPRM, Brasília, Editora UnB, 392 p.

Góes A.M.O. \& Feijó F.J. 1994. Bacia do Parnaíba. Boletim de Geociências da Petrobrás, 8:57-67.

Grandjean-Lécuyer P., Feist R., Albaréde F. 1993. Rare earth elements in old biogenic apatites. Geochimica et Cosmochimica Acta, 57:2507-2514.

Gromet L.P., Dymek R.F., Haskin L.A., Korotev. R.L. 1984. The North American Shale Composite: its compilation, major and trace element characteristics. Geochimica Cosmochimica Acta, 48:2469-2482.

Guilbert J.M. \& Park Jr C.F. 1986. The geology of ore deposits, New York, W.H. Freeman Co., 985 p.

Heikkoop J.M., Tsujita C.J., Risk M.J., Tomascik T., Mah A.J. 1996. Modern iron ooids from a shallow-marine volcanic setting: Mahengetang, Indonesia. Geology, 24:759-762

Henderson P. (Ed.). 1984. Rare earth element geochemistry. Amsterdam, Elsevier, $510 \mathrm{p}$.

Hennies W.T. 1969. Minério de ferro oolítico no Brasil. In: SBG, Congresso Brasileiro de Geologia, 23, Anais, p. 177-182.

Kegel W. 1953. Contribuição para o estudo do Devoniano da bacia do Parnaíba. Boletim da Divisão de Geologia e Mineralogia, DNPM. Rio de Janeiro, p. 141-148.
Kimberley M.M. 1994. Debate about ironstone: Has solute supply been surficial weathering, hydrothermal convection, or exhalation of deep fluids? Terra Nova, 6:116-132.

Krachler R., Krachler R.F., Von der Kammer F., Süphandag A., Jirsa F., Ayromlou S., Hofmann T., Keppler B.K. 2010. Relevance of peat-draining rivers for the riverine input of dissolved iron into the ocean. Science of the Total Environment, 408:2402-2408.

Lee C.H. \& Lee H.K. 2003. Vanadium and barium-bearing green mica within coaly metapelite from the Ogcheon Supergroup, Republic of Korea, Journal of Asian Earth Sciences, 21:343-351.

Lijklema L. 1980. Interaction of orthophosphate with iron (III) and aluminum hydroxides. Environmental Science \& Technology, 14:537-541.

Mendelovici E., Yariv S.H., Villalba R. 1979. Iron-bearing kaolinites in Venezuelan laterites: infrared spectroscopy and chemical dissolution evidence. Clay Minerals, 14:323-331.

Milani E.J. \& Zalán P.V. 1999. An outline of the geology and petroleum systems of the Paleozoic interior basins of South America. Episodes, 22:199-205.

Moura C.A.V. \& Gaudette H. 1993. Evidence of Brasiliano / Panafrican deformation in the Araguaia Belt: implication for Gondwana evolution. Revista Brasileira de Geociências, 23:117-123.

Nahon D., Carozzi A.V., Parron C. 1980. Lateritic weathering as a mechanism for the generation of ferruginous ooids. Journal of Sedimentary Petrolology, 50:1287-1298.

Nash J.T., Granger H.C., Adams S.S. 1981. Geology and concepts of genesis of important types of uranium deposits. Economic Geology, $75^{\text {th }}$ Anniversary Volume, p. 63-116.

Ohkawa M., Miyahara M., Ohta E., Koshino K. 2007. Silicon-substituted magnetite and accompanying iron oxides and hydroxides ROM the Kumano mine, Yamaguchi Prefecture, Japan: re-examination of the socalled maghemite $\left(\gamma-\mathrm{Fe}_{2} \mathrm{O}_{3}\right)$. Journal of Mineralogical and Petrological Science, 102:182-193.

Peacock C.L. \& Sherman D.M. 2004. Vanadium (V) adsorption onto goethite $(\alpha-\mathrm{FeOOH})$ at $\mathrm{pH} 1.5$ to 12: A surface complexation model based on ab initio molecular geometries and EXAFS spectroscopy. Geochimica et Cosmochimica Acta, 68:1723-1733.

Piasecki W. \& Sverjensky D.A. 2008. Speciation of adsorbed yttrium and rare earth elements on oxide surfaces. Geochimica et Cosmochimica Acta, 72:39643979. 
Ribeiro C.C. \& Dardenne M.A. 1978. O minério de ferro da Formação Pimenteiras na borda SW da Bacia do Maranhão (Goiás). In: SBG, Congresso Brasileiro de Geologia, 30, Anais, v. 4, p. 1583-1595.

Ribeiro C.C. 1984. Caractérisation sédimentologique et géochimique d'un milieu sédimentaire. Cas $d u$ Dévonien Moyen et Supérieur de la Région de Paraíso do Norte - Miranorte (Bassin de Maranhão, Goiás, Brésil). Thèse Docteur de $3^{\text {ème }}$ cycle. I'Institut National Polytechinique de Lorraine. 252p.

Robb L.J. 2005. Introduction to ore-forming processes, New York, Blackwell Publ. Co. 377p.

Sá C.M.G. 1981. Considerações sobre mineralizações de zinco e ferro associadas à Formação Pimenteiras (Bacia Maranhão-Borda Oeste). In: SBG, Núcleo Centro-Oeste, Boletim Informativo, 10:9-32.

Sanyal S.K. \& De Datta S.K. 1991. Chemistry of phosphorus transformations in soil. Advanced Soil Science, 16:1-120.

Schwertmann U. \& Pfab G. 1996. Structural vanadium and chromium in lateritic iron oxides: genetic implications. Geochimica et Cosmochimica Acta, 60:4279-4283.
Siehl A. \& Thein J. 1989. Ironstones type Minette. Geological Society of London, Special Publications, 46:175-193.

Solymar K. 1969. Alumogoethit in den ungarischen Bauxiten: Annals of the Hungary Geological Institute Publications, 54:359-373.

Stanton R.L. 1972. Ore Petrology. New York, Mc GrawHill, 713 p.

Sturesson U. 1995. Llanvirnian (Ord.) iron ooides in Baltoscandia: element mobility, REE distribuition patterns and origin of the REE. Chemical Geology, 125:45-60.

Sturesson U., Heikoop J.M., Risk M.J. 2000. Modern and Paleozoic iron ooids - a similar volcanic origin. Sedimentary Geology, 136:137-146.

Young T.P. 1989. Phanerozoic ironstones: an introduction and review. In: Young T.P. \& Taylor W.E.G. (ed.) Phanerozoic Ironstones, Geological Society of London, Special Publication 46, ix-xxv.

Manuscrito ID 20555

Recebido em: 17/01/2011

Aprovado em: 07/03/2012 
Anexo - Análises de EDS

\begin{tabular}{|c|c|c|c|c|c|}
\hline \multicolumn{6}{|c|}{ ZIRCÃO } \\
\hline \multicolumn{2}{|c|}{53 a 500x 64986-1 } & \multicolumn{2}{|c|}{ 53a 500x 64988-1 } & \multicolumn{2}{|c|}{ 53a 450x 64995-5 zircão } \\
\hline Elt. & Conc & Elt. & Conc & Elt. & Conc \\
\hline $\mathrm{O}$ & 24,533 & $\mathrm{O}$ & 24,103 & $\mathrm{O}$ & 25,248 \\
\hline $\mathrm{Si}$ & 11,749 & $\mathrm{Si}$ & 11,784 & $\mathrm{Si}$ & 11,757 \\
\hline $\mathrm{Y}$ & 0,000 & $\mathrm{Y}$ & 0,000 & $\mathrm{Y}$ & 0,000 \\
\hline $\mathrm{Zr}$ & 55,985 & $\mathrm{Zr}$ & 55,811 & $\mathrm{Zr}$ & 54,729 \\
\hline $\mathrm{La}$ & 0,333 & $\mathrm{La}$ & 0,433 & $\mathrm{La}$ & 0,440 \\
\hline $\mathrm{Ce}$ & 0,314 & $\mathrm{Ce}$ & 0,306 & $\mathrm{Ce}$ & 0,239 \\
\hline $\mathrm{Pr}$ & 0,320 & $\mathrm{Pr}$ & 0,000 & $\mathrm{Pr}$ & 0,163 \\
\hline $\mathrm{Nd}$ & 0,000 & $\mathrm{Nd}$ & 0,158 & $\mathrm{Nd}$ & 0,000 \\
\hline $\mathrm{Pm}$ & 0,051 & $\mathrm{Pm}$ & 0,212 & $\mathrm{Pm}$ & 0,242 \\
\hline $\mathrm{Sm}$ & 0,000 & $\mathrm{Sm}$ & 0,052 & $\mathrm{Sm}$ & 0,137 \\
\hline $\mathrm{Eu}$ & 0,540 & $\mathrm{Eu}$ & 0,526 & $\mathrm{Eu}$ & 0,570 \\
\hline $\mathrm{Gd}$ & 0,494 & $\mathrm{Gd}$ & 0,532 & $\mathrm{Gd}$ & 0,111 \\
\hline $\mathrm{Tb}$ & 0,370 & $\mathrm{~Tb}$ & 0,393 & $\mathrm{~Tb}$ & 0,711 \\
\hline Dy & 0,564 & Dy & 0,689 & Dy & 1,111 \\
\hline Ho & 0,254 & Ho & 0,000 & Ho & 0,134 \\
\hline $\mathrm{Er}$ & 0,317 & $\mathrm{Er}$ & 0,420 & Er & 0,145 \\
\hline $\mathrm{Tm}$ & 0,744 & $\mathrm{Tm}$ & 0,245 & $\mathrm{Tm}$ & 0,558 \\
\hline $\mathrm{Yb}$ & 0,177 & $\mathrm{Yb}$ & 0,570 & $\mathrm{Yb}$ & 0,000 \\
\hline $\mathrm{Lu}$ & 0,407 & $\mathrm{Lu}$ & 0,231 & $\mathrm{Lu}$ & 0,240 \\
\hline $\mathrm{Hf}$ & 1,063 & Hf & 1,270 & Hf & 1,882 \\
\hline $\mathrm{Pb}$ & 1,347 & $\mathrm{~Pb}$ & 1,822 & $\mathrm{~Pb}$ & 1,243 \\
\hline $\mathrm{Th}$ & 0,319 & Th & 0,226 & $\mathrm{Th}$ & 0,038 \\
\hline $\mathrm{U}$ & 0,119 & $\mathrm{U}$ & 0,218 & $\mathrm{U}$ & 0,303 \\
\hline Total & 100,000 & Total & 100,000 & Total & 100,000 \\
\hline \multicolumn{2}{|c|}{ 53b 320x 64998-4 zircão } & \multicolumn{2}{|c|}{53 b 500x 65009-4 } & \multicolumn{2}{|c|}{$53 \mathrm{~d} 750 \times 65026-2$} \\
\hline Elt. & Conc & Elt. & Conc & Elt. & Conc \\
\hline $\mathrm{O}$ & 27,833 & $\mathrm{O}$ & 28,637 & $\mathrm{O}$ & 24,320 \\
\hline $\mathrm{Si}$ & 11,800 & $\mathrm{Si}$ & 9,774 & $\mathrm{Si}$ & 11,862 \\
\hline $\mathrm{Y}$ & 0,000 & $\mathrm{Fe}$ & 2,028 & $\mathrm{Y}$ & 0,000 \\
\hline $\mathrm{Zr}$ & 52,737 & $\mathrm{Y}$ & 0,367 & $\mathrm{Zr}$ & 56,013 \\
\hline $\mathrm{La}$ & 0,444 & $\mathrm{Zr}$ & 50,952 & $\mathrm{La}$ & 0,212 \\
\hline $\mathrm{Ce}$ & 0,270 & $\mathrm{La}$ & 0,182 & $\mathrm{Ce}$ & 0,289 \\
\hline $\operatorname{Pr}$ & 0,000 & $\mathrm{Ce}$ & 0,891 & $\operatorname{Pr}$ & 0,124 \\
\hline $\mathrm{Nd}$ & 0,000 & $\mathrm{Pr}$ & 0,180 & $\mathrm{Nd}$ & 0,289 \\
\hline $\mathrm{Pm}$ & 0,035 & $\mathrm{Nd}$ & 0,257 & $\mathrm{Pm}$ & 0,126 \\
\hline $\mathrm{Sm}$ & 0,325 & $\mathrm{Pm}$ & 0,000 & Sm & 0,063 \\
\hline $\mathrm{Eu}$ & 0,648 & $\mathrm{Sm}$ & 0,000 & $\mathrm{Eu}$ & 0,732 \\
\hline $\mathrm{Gd}$ & 0,245 & $\mathrm{Eu}$ & 0,189 & $\mathrm{Gd}$ & 0,238 \\
\hline $\mathrm{Tb}$ & 0,543 & $\mathrm{Gd}$ & 0,371 & $\mathrm{~Tb}$ & 0,618 \\
\hline Dy & 0,763 & $\mathrm{~Tb}$ & 0,000 & Dy & 0,313 \\
\hline Ho & 0,062 & Dy & 1,130 & Ho & 0,000 \\
\hline Er & 0,000 & Ho & 0,000 & $\mathrm{Er}$ & 0,000 \\
\hline $\mathrm{Tm}$ & 0,572 & $\mathrm{Er}$ & 0,094 & Tm & 0,350 \\
\hline $\mathrm{Yb}$ & 0,040 & $\mathrm{Tm}$ & 0,000 & $\mathrm{Yb}$ & 0,659 \\
\hline $\mathrm{Lu}$ & 0,389 & $\mathrm{Yb}$ & 0,528 & $\mathrm{Lu}$ & 0,139 \\
\hline $\mathrm{Hf}$ & 1,353 & $\mathrm{Lu}$ & 0,174 & $\mathrm{Hf}$ & 2,232 \\
\hline $\mathrm{Pb}$ & 1,569 & $\mathrm{Hf}$ & 2,048 & $\mathrm{~Pb}$ & 1,026 \\
\hline $\mathrm{Th}$ & 0,159 & $\mathrm{~Pb}$ & 1,759 & $\mathrm{Th}$ & 0,079 \\
\hline $\mathrm{U}$ & 0,213 & $\mathrm{Th}$ & 0,114 & U & 0,315 \\
\hline \multirow[t]{2}{*}{ Total } & 100,000 & $\mathrm{U}$ & 0,324 & Total & 100,000 \\
\hline & & Total & 100,000 & & \\
\hline
\end{tabular}

\begin{tabular}{cc}
\hline \multicolumn{2}{c}{ MONAZITA } \\
\hline 53b 320x 64998-1 monazita \\
\hline Elt. & Conc \\
\hline $\mathrm{O}$ & 26.681 \\
\hline $\mathrm{P}$ & 16.542 \\
\hline $\mathrm{La}$ & 9.956 \\
\hline $\mathrm{Ce}$ & 26.850 \\
\hline $\mathrm{Pr}$ & 0.000 \\
\hline $\mathrm{Nd}$ & 9.114 \\
\hline $\mathrm{Pm}$ & 0.000 \\
\hline $\mathrm{Sm}$ & 0.178 \\
\hline $\mathrm{Eu}$ & 0.513 \\
\hline $\mathrm{Gd}$ & 0.853 \\
\hline $\mathrm{Tb}$ & 0.000 \\
\hline $\mathrm{Dy}$ & 0.000 \\
\hline $\mathrm{Ho}$ & 0.000 \\
\hline $\mathrm{Er}$ & 0.276 \\
\hline $\mathrm{Tm}$ & 0.973 \\
\hline $\mathrm{Yb}$ & 0.796 \\
\hline $\mathrm{Lu}$ & 1.772 \\
\hline $\mathrm{Th}$ & 5.402 \\
\hline $\mathrm{U}$ & 0.095 \\
\hline $\mathrm{Total}$ & 100.000 \\
\hline
\end{tabular}



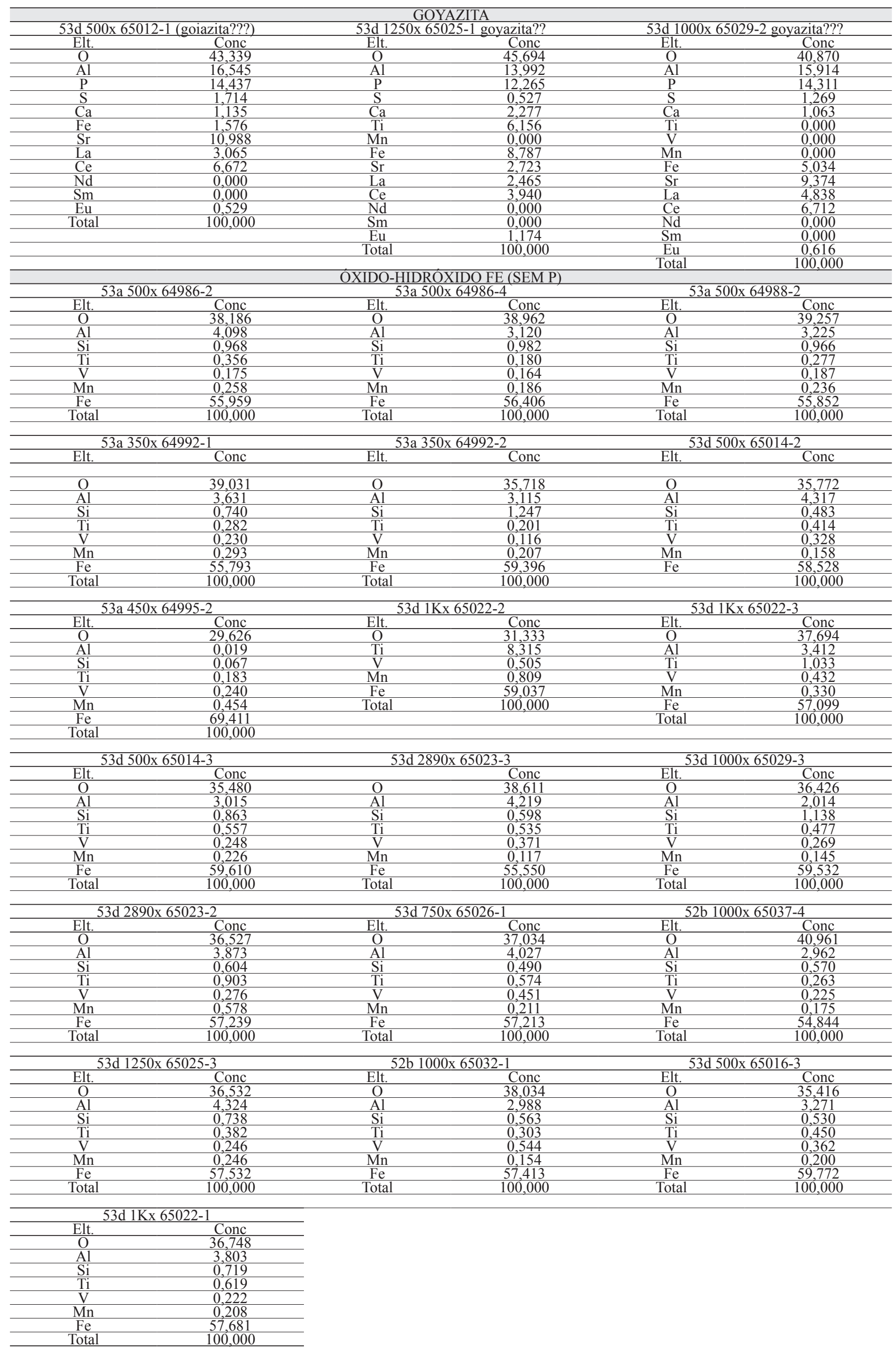


\begin{tabular}{|c|c|c|c|c|c|}
\hline \multicolumn{6}{|c|}{ OXIDO-HIDRÓXIDO FE (COM P) } \\
\hline \multicolumn{2}{|c|}{ 53a 350x 64992-1 com P } & \multicolumn{2}{|c|}{$53 \mathrm{a} 350 \times 64992-2$ com P } & \multicolumn{2}{|c|}{ 53b 320x 64998-2 } \\
\hline Elt. & Conc & Elt. & Conc & Elt. & Conc \\
\hline $\mathrm{O}$ & 38,988 & $\mathrm{O}$ & 35,704 & $\mathrm{O}$ & 40,886 \\
\hline $\mathrm{Al}$ & 3,407 & $\mathrm{Al}$ & 2,897 & $\mathrm{Al}$ & 2,457 \\
\hline $\mathrm{Si}$ & 0,694 & $\mathrm{Si}$ & 1,160 & $\mathrm{Si}$ & 0,449 \\
\hline $\mathrm{P}$ & 2,650 & $\mathrm{P}$ & 3,099 & $\mathrm{P}$ & 1,936 \\
\hline $\mathrm{Ti}$ & 0,274 & $\mathrm{Ti}$ & 0,196 & $\mathrm{Ti}$ & 0,585 \\
\hline $\mathrm{V}$ & 0,226 & $\mathrm{~V}$ & 0,114 & $\mathrm{~V}$ & 0,482 \\
\hline $\mathrm{Mn}$ & 0,283 & $\mathrm{Mn}$ & 0,199 & $\mathrm{Mn}$ & 0,184 \\
\hline $\mathrm{Fe}$ & 53,478 & $\mathrm{Fe}$ & 56,631 & $\mathrm{Fe}$ & 53,021 \\
\hline Total & 100,000 & Total & 100,000 & Total & 100,000 \\
\hline \multicolumn{2}{|c|}{ 53b 500x 65000-1 } & \multicolumn{2}{|c|}{ 53b 500x 65000-5 idem pt 1} & \multicolumn{2}{|c|}{$53 b 350 \times 65004-2$} \\
\hline Elt. & Conc & Elt. & Conc & Elt. & Conc \\
\hline $\mathrm{O}$ & 38,735 & $\mathrm{O}$ & 38,406 & $\mathrm{O}$ & 38,760 \\
\hline $\mathrm{Al}$ & 1,800 & $\mathrm{Al}$ & 1,401 & $\mathrm{Al}$ & 2,932 \\
\hline $\mathrm{Si}$ & 0,417 & $\mathrm{Si}$ & 0,585 & $\mathrm{Si}$ & 0,219 \\
\hline $\mathrm{P}$ & 2,597 & $\mathrm{P}$ & 3,189 & $\mathrm{P}$ & 2,681 \\
\hline $\mathrm{Ti}$ & 0,486 & $\mathrm{Ti}$ & 0,099 & $\mathrm{Ti}$ & 0,985 \\
\hline $\mathrm{V}$ & 0,444 & V & 0,137 & $\mathrm{~V}$ & 0,522 \\
\hline $\mathrm{Mn}$ & 0,186 & $\mathrm{Mn}$ & 0,259 & $\mathrm{Mn}$ & 0,446 \\
\hline $\mathrm{Fe}$ & 55,335 & $\mathrm{Fe}$ & 55,924 & $\mathrm{Fe}$ & 53,454 \\
\hline Total & 100,000 & Total & 100,000 & Total & 100,000 \\
\hline \multicolumn{2}{|c|}{$53 \mathrm{~b} 350 \times 65004-4$} & \multicolumn{2}{|c|}{ 53b 500x 65009-1 } & \multicolumn{2}{|c|}{53 b 500x 65009-2 } \\
\hline Elt. & Conc & Elt. & Conc & Elt. & Conc \\
\hline $\mathrm{O}$ & 49,779 & $\mathrm{O}$ & 42,762 & $\mathrm{O}$ & 39,798 \\
\hline $\mathrm{Al}$ & 1,593 & $\mathrm{Al}$ & 10,590 & $\mathrm{Al}$ & 2,967 \\
\hline $\mathrm{Si}$ & 1,782 & $\mathrm{Si}$ & 0,694 & $\mathrm{Si}$ & 0,607 \\
\hline $\mathrm{P}$ & 0,215 & $\mathrm{P}$ & 2,459 & $\mathrm{P}$ & 2,926 \\
\hline $\mathrm{Ti}$ & 0,135 & $\mathrm{Ti}$ & 0,129 & $\mathrm{Ti}$ & 0,324 \\
\hline $\mathrm{V}$ & 0,108 & $\mathrm{~V}$ & 0,137 & $\mathrm{~V}$ & 0,218 \\
\hline $\mathrm{Mn}$ & 0,088 & $\mathrm{Mn}$ & 0,096 & $\mathrm{Mn}$ & 0,169 \\
\hline $\mathrm{Fe}$ & 46,301 & $\mathrm{Fe}$ & 43,133 & $\mathrm{Fe}$ & 52,989 \\
\hline Total & 100,000 & Total & 100,000 & Total & 100,000 \\
\hline \multicolumn{2}{|c|}{$53 \mathrm{~d} 500 \times 65012-3$} & \multicolumn{2}{|c|}{$53 \mathrm{~d} 500 \times 65012-5$} & & \\
\hline Elt. & Conc & Elt. & Conc & & \\
\hline $\mathrm{O}$ & 37,428 & $\mathrm{O}$ & 33,034 & & \\
\hline $\mathrm{Al}$ & 3,476 & $\mathrm{Al}$ & 2,530 & & \\
\hline $\mathrm{Si}$ & 0,601 & $\mathrm{Si}$ & 0,952 & & \\
\hline $\mathrm{P}$ & 3,062 & $\mathrm{P}$ & 3,572 & & \\
\hline $\mathrm{Ti}$ & 0,484 & $\mathrm{Ti}$ & 0,116 & & \\
\hline $\mathrm{V}$ & 0,301 & $\mathrm{~V}$ & 0,087 & & \\
\hline $\mathrm{Mn}$ & 0,271 & $\mathrm{Mn}$ & 0,225 & & \\
\hline $\mathrm{Fe}$ & 54,377 & $\mathrm{Fe}$ & 59,485 & & \\
\hline Total & 100,000 & Total & 100,000 & & \\
\hline \multicolumn{4}{|c|}{ ILMENITA } & & \\
\hline \multicolumn{2}{|c|}{$53 \mathrm{~d} 500 \times 65014-1$} & \multicolumn{2}{|c|}{$53 \mathrm{~d} \mathrm{1000 \times} \mathrm{65029-1}$} & & \\
\hline Elt. & Conc & Elt. & Conc & & \\
\hline $\mathrm{O}$ & 46,124 & $\mathrm{O}$ & 44,249 & & \\
\hline $\mathrm{Al}$ & 5,004 & $\mathrm{Ti}$ & 37,075 & & \\
\hline $\mathrm{Si}$ & 0,806 & $\mathrm{~V}$ & 0,741 & & \\
\hline $\mathrm{Ca}$ & 0,770 & $\mathrm{Mn}$ & 0,679 & & \\
\hline $\mathrm{Ti}$ & 28,192 & $\mathrm{Fe}$ & 17,256 & & \\
\hline $\mathrm{V}$ & 0,535 & Total & 100,000 & & \\
\hline $\mathrm{Mn}$ & 0,181 & & & & \\
\hline $\mathrm{Fe}$ & 18,388 & & & & \\
\hline & 100,000 & & & & \\
\hline
\end{tabular}




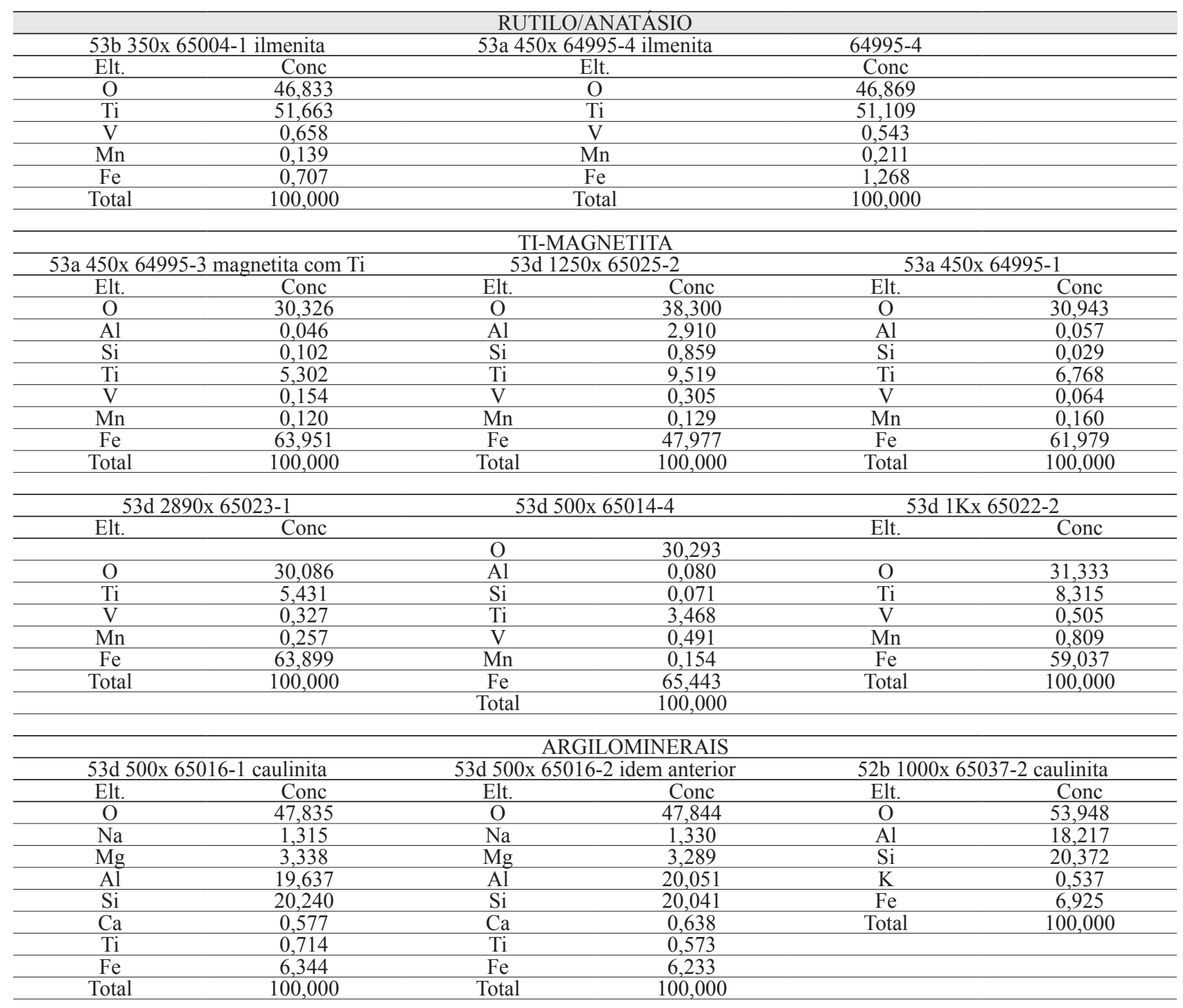

